University of Northern lowa

UNI ScholarWorks

\title{
Self-defeating behaviors in sexual offenders: Exploring factors of social support and motivation to change
}

Cassie Rose Nieman

University of Northern lowa

Let us know how access to this document benefits you

Copyright (C2012 Cassie Rose Nieman

Follow this and additional works at: https://scholarworks.uni.edu/etd

Part of the Psychology Commons

\section{Recommended Citation}

Nieman, Cassie Rose, "Self-defeating behaviors in sexual offenders: Exploring factors of social support and motivation to change" (2012). Dissertations and Theses@UNI. 548.

https://scholarworks.uni.edu/etd/548

This Open Access Thesis is brought to you for free and open access by the Student Work at UNI ScholarWorks. It has been accepted for inclusion in Dissertations and Theses @ UNI by an authorized administrator of UNI ScholarWorks. For more information, please contact scholarworks@uni.edu. 
SELF-DEFEATING BEHAVIORS IN SEXUAL OFFENDERS:

EXPLORING FACTORS OF SOCIAL SUPPORT

AND MOTIVATION TO CHANGE

\author{
An Abstract of a Thesis \\ Submitted \\ in Partial Fulfillment \\ of the Requirements for the Degree \\ Master of Arts
}

Cassie Rose Nieman

University of Northern Iowa

May, 2012 


\begin{abstract}
Sexual offenders often engage in self-defeating behaviors that affect their treatment progress. Self-defeating behaviors are those that are dynamic in nature and change over time throughout the course of treatment. Certain aspects of an offender's life may play a role in whether and how often these behaviors occur, such as the level of social support on which the offender can rely. A second factor is the degree of motivation an offender has to change his behavior. The purpose of this study was to determine if and how the factors of social support systems and motivation to change impact self-defeating
\end{abstract} behaviors. Participants in this study included 74 civilly committed sex offenders at the Civil Commitment Unit for Sex Offenders in Cherokee, Iowa. To determine selfdefeating behavior, archival records from each offender were analyzed and questionnaires were administered to gather this information as well as to measure social support and motivation to change. When offenders rate their own self-defeating behaviors, social support systems and motivation to change do play a role; more perceived social support and higher levels of motivation to change decrease self-defeating behaviors. Results indicate that social support and motivation to change do not play a significant role in selfdefeating behaviors when rated by therapists. The amount of social support and the level of motivation to change do not affect progression through treatment. Future research should focus on additional factors that may impact treatment progress (e.g., mental abnormalities). All civilly committed sexual offenders, specifically in Iowa, are determined to have a mental abnormality by the state through a process of civil hearings; 
thus resulting in being detained indefinitely. The mental abnormality could prolong progression through treatment; however, if it does not play a role in treatment progression, the guidelines to successfully complete treatment in civil commitment units should be examined further. 
SELF-DEFEATING BEHAVIORS IN SEXUAL OFFENDERS:

EXPLORING FACTORS OF SOCIAL SUPPORT

AND MOTIVATION TO CHANGE

\author{
A Thesis \\ Submitted \\ in Partial Fulfillment \\ of the Requirements for the Degree \\ Master of Arts
}

Cassie Rose Nieman

University of Northern Iowa

May, 2012 
This study by: Cassie Nieman

Entitled: Self-Defeating Behaviors in Sexual Offenders: Exploring Factors of Social Support and Motivation to Change

has been approved as meeting the thesis requirements for the Degree of Master of Arts.

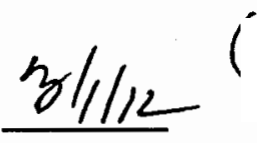

Date Dr. Kim MacLin, Chair, Thesis Committee

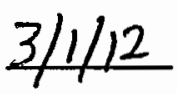

Date

Dr. John E. Williams, Thesis Committee Member

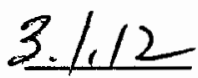

Date

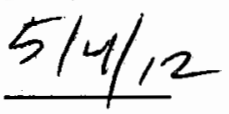

Dr. Mary Losch, Thesis Committee Member

Date

Dr. Michael J. Licari, Dean, Graduate College 


\section{ACKNOWLEDGEMENTS}

Thanks are due to my thesis committee chair, Kim MacLin, especially in times of stress and feeling like the process of writing a thesis would never end. I appreciate the pep talks and support throughout the last 450 days (or so (-)). I would also like to thank my committee members, Mary Losch, and John Williams, for their help with this project. John, I am grateful you were in Psych 1 the majority of the time in case I had a question that required an immediate answer. Mary, I am grateful for the direct answers regarding the procedural aspects of this paper.

Thank you to Dr. Ryan and the treatment team at CCUSO for allowing us to use their facility to conduct this study. I owe a big thank you to Mike Whitson for help with stats on this project; without you I would have had to move my apartment into Psych 1 for the semester. For all the other clinical students who had to listen to me during some of my finest moments, I appreciate the support and positive feedback.

I would not be where I am today if it were not for my wonderful parents, Marty and Patti. They have been there through every step of the way and have provided support in ways I cannot begin to describe. Last, but not least, I owe my sanity to Ashley Helle for being my partner in crime during this last year and a half. This program has not only allowed me to grow on so many levels, it has allowed me to gain a friendship that is difficult to come by in a lifetime. 


\section{TABLE OF CONTENTS}

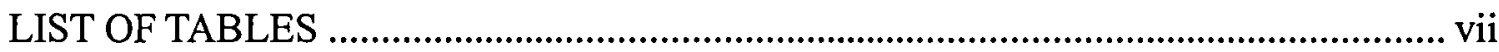

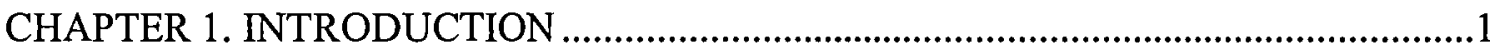

Sexual Offending and Offender Characteristics .........................................................

Policies and Treatment for Sexual Offenders .............................................................3

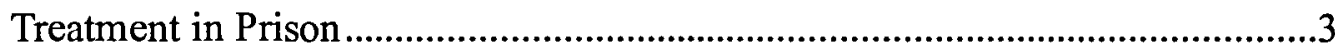

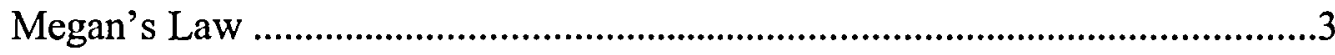

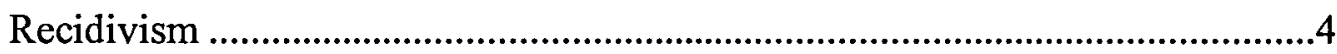

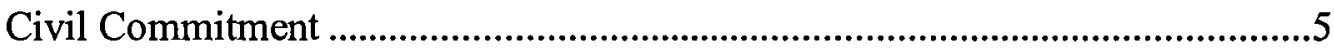

Treatment during civil confinement..........................................................

Obstacles to Positive Treatment Outcomes.......................................................................8

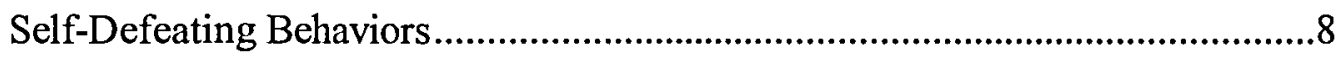

Protective Factors for Treatment Success ................................................................11

Social Support Systems....................................................................................11

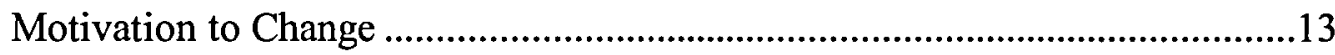

Motivation and treatment .......................................................................15

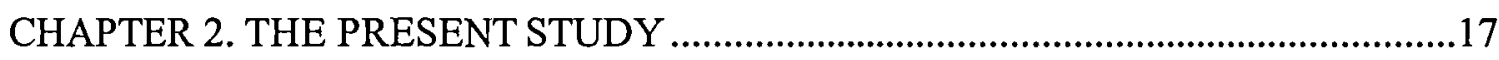

Statement of Purpose ....................................................................................................17

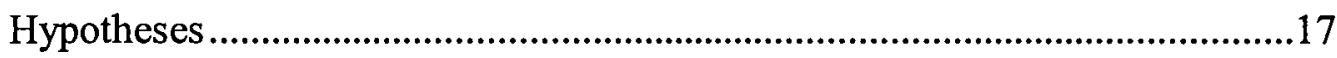

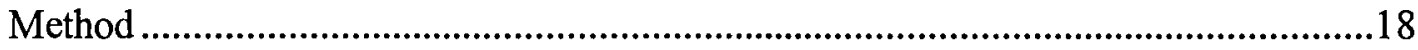

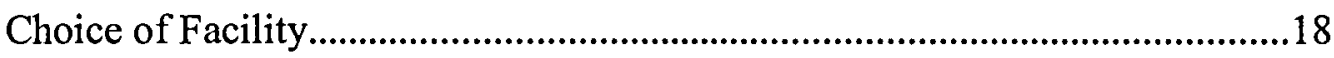

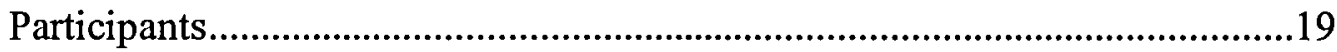

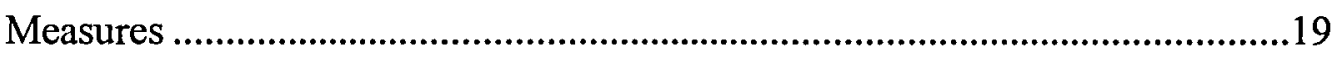

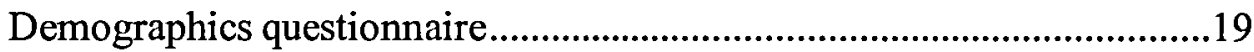

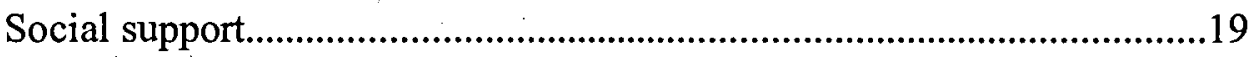

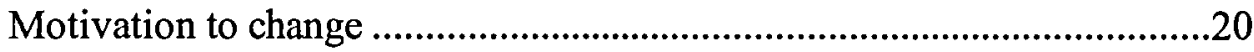

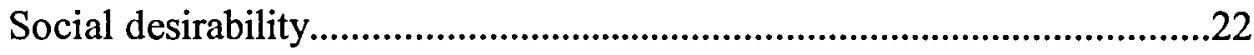

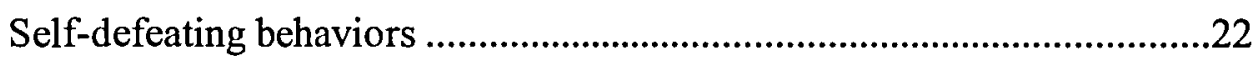

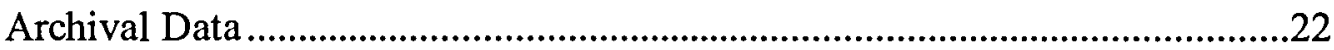




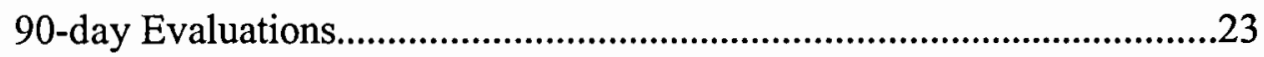

Stable

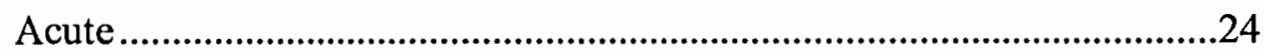

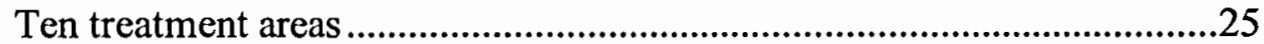

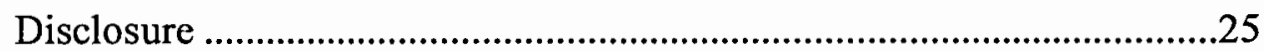

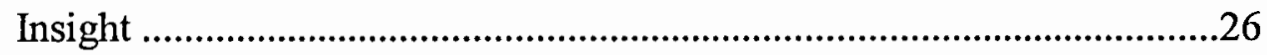

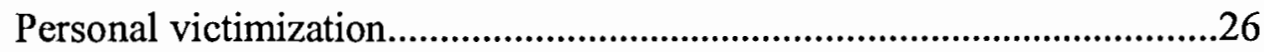

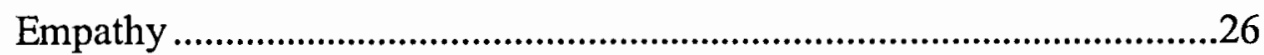

Health, hygiene, and leisure skills .............................................................26

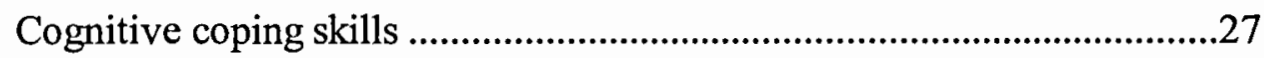

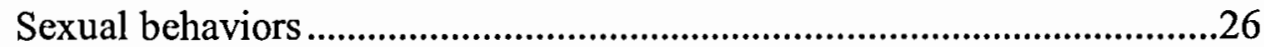

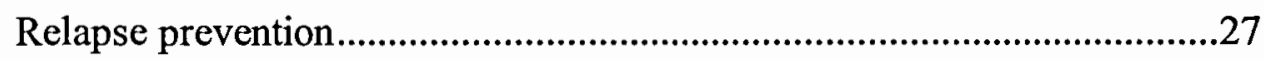

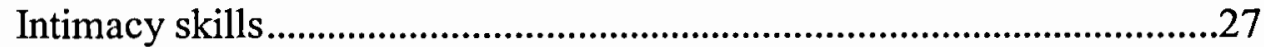

Problem solving skills........................................................................28

Phases of treatment ....................................................................................28

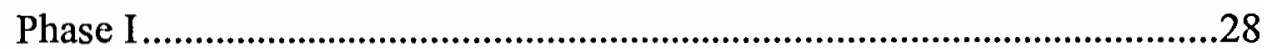

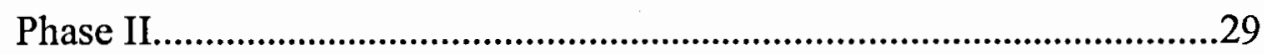

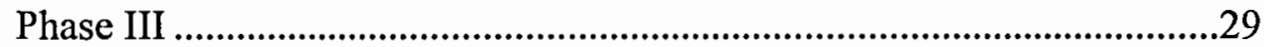

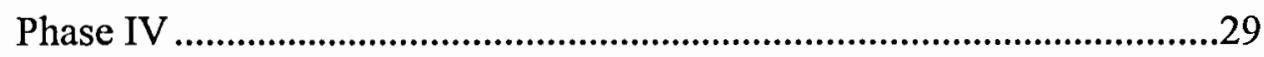

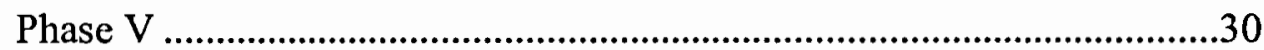

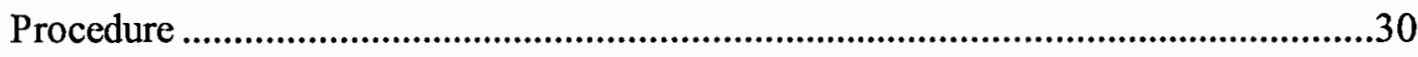

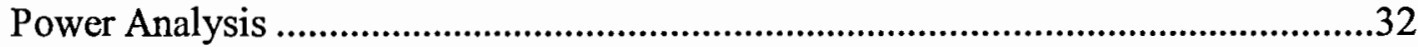

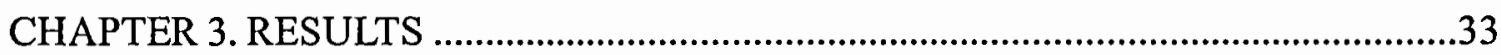

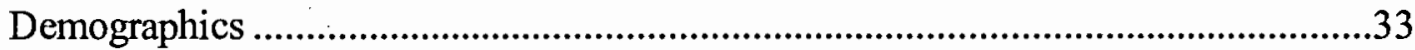

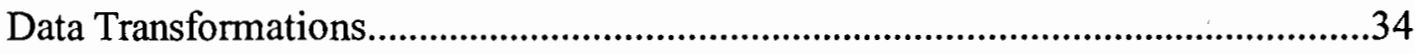

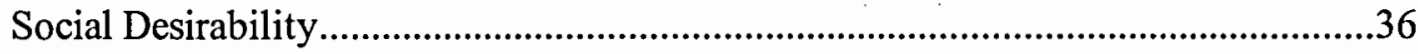

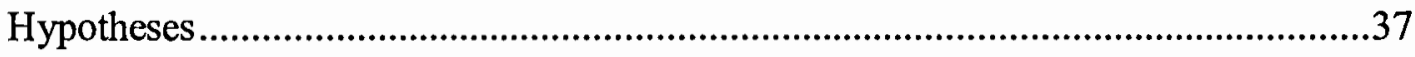

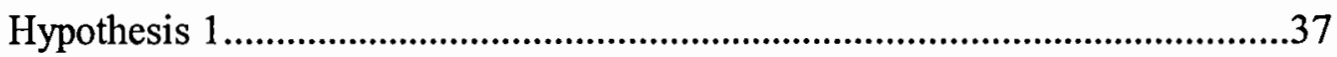

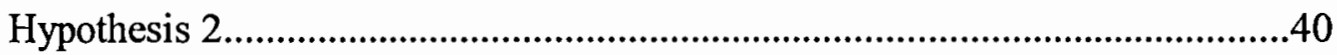




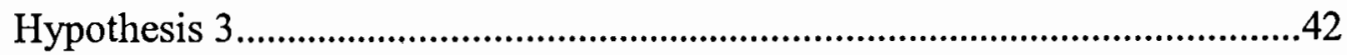

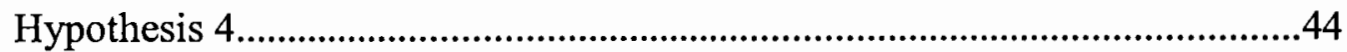

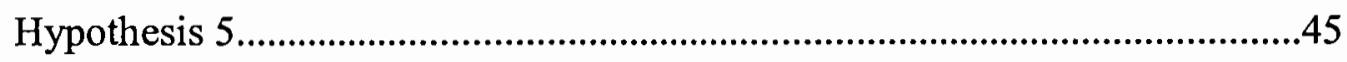

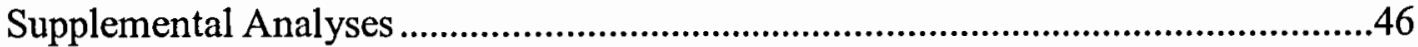

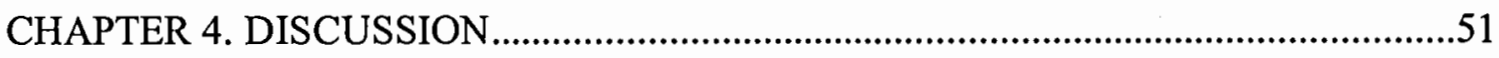

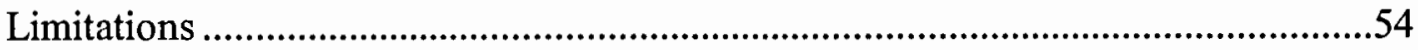

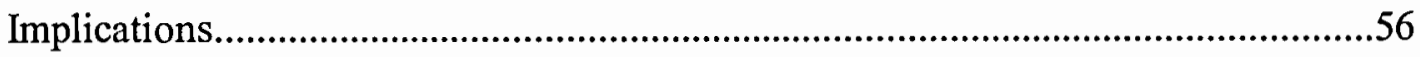

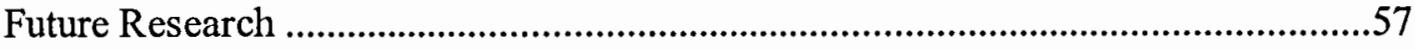

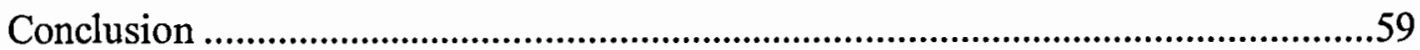

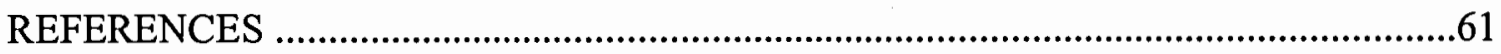

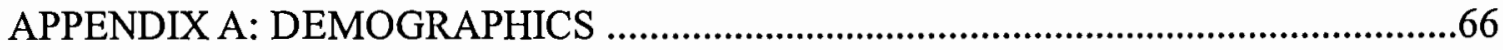

APPENDIX B: SOURCE-SPECIFIC SOCIAL PROVISIONS SCALE ..........................69

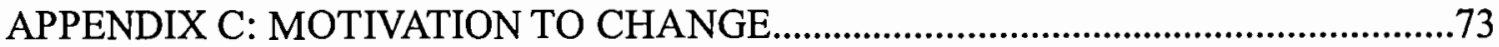

APPENDIX D: MARLOWE-CROWNE SOCIAL DESIRABILITY SCALE .................75

APPENDIX E: SELF-DEFEATING BEHAVIOR QUESTIONNAIRE ............................78

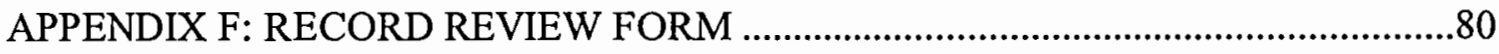

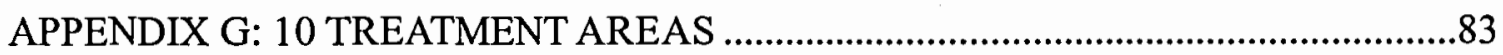

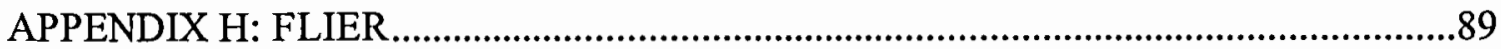

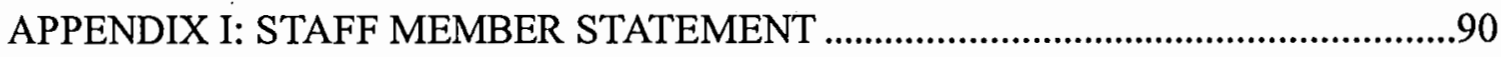

APPENDIX J: STATEMENT OF PURPOSE _................................................................

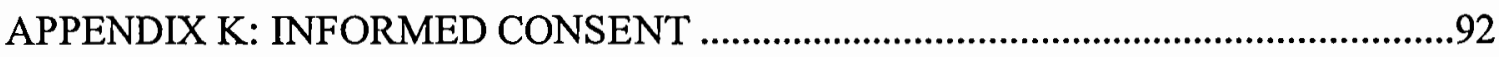

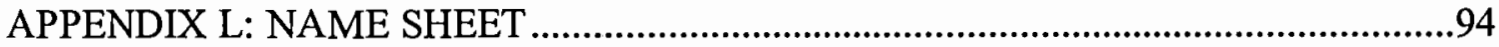




\section{LIST OF TABLES}

TABLE

PAGE

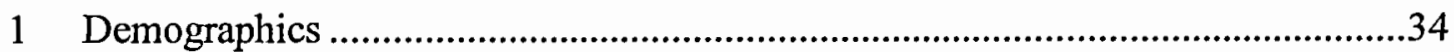

2 Correlations Between Social Desirability and Self-Report Questionnaires ...........36

3 Mean and Standard Deviations for the Self-Defeating Questionnaire, URICA, Source-Specific Social Provisions Scale, and Social Desirability Scale .................37

4 Intercorrelations Between Subscales and Total Readiness on the University of Rhode Island Change Assessment Scale...................................................................38

5 Intercorrelations Between Subscales and Total Social Support on the SourceSpecific Social Provisions Scale...........................................................................39

6 Correlations Between Social Support and Self-Defeating Behaviors.......................41

7 Correlations Between Motivation to Change and Self-Defeating Behaviors .........42

8 Correlations Between Self-Defeating Measures and Average Time in a Phase.....43

9 Correlations Between Motivation Subscales and Total Length of Commitment...45

10 Correlations Between Self-Defeating Questionnaire and Defeating Behaviors Reported by the Therapists ................................................................................4

11 Correlations Between Self-Defeating Behaviors and Social Support ....................47

12 Correlations Between Self-Defeating Behaviors and Motivation to Change ........48

13 Partial Correlations Between Social Support and 10 Treatment Areas...................49

14 Partial Correlations Between Motivation to Change and 10 Treatment Areas ......50 


\section{CHAPTER 1}

\section{INTRODUCTION}

Sexual offenses are often viewed as some of the most severe crimes against vulnerable populations (e.g., women and children; Bureau of Justice Statistics, 2003). Sexual offenders are often at a disadvantage due to civil commitment laws (Miller, 2010). Civil commitment laws hold that sexual offenders who are deemed more likely than not to reoffend, have a mental abnormality (e.g., congenital or acquired) that predisposes a person to commit sexually violent offences, and who are labeled a sexually violent predator are to be detained indefinitely even after they have served their prison sentences (Miller, 2010). This is not a second prison sentence, but their release is dependent on completion of an intensive treatment program, and approval from a civil court before they can be reintegrated into the community.

Successful completion of treatment is difficult and many states that have civil commitment laws have few offenders who have been discharged. As of 2006 , only $9 \%$ of the 2, 694 civilly committed offenders in eighteen states have ever been fully discharged (Burns, 2009). In treatment, offenders are required to disclose their sexual feelings, admit responsibility for their crime, control their sexual behavior, and exhibit appropriate reactions to stress. Further, most offenders are well aware that life may be difficult after release, with concerns about registry, how much support they will receive from family and friends, living arrangements, relationships, employment, and fears about reoffending. Combined, these may all lead to a lack of motivation to change, and the display of self-defeating behaviors to hinder treatment progress and eventual release. 
Progress through treatment is determined by therapist evaluations every 90 days. Aspects of the offender's progress in the treatment program include: level of insight, disclosure of sexual offenses, intimacy and problem solving skills, and sexual behaviors. Scores on these evaluations determine which phase of treatment the offender can advance to, if at all.

The goal of the current study was to determine if lack of social support and low motivation to change is an obstacle to successful advancement through treatment. Lack of social support may play a role in self-defeating behaviors. If an offender does not have a positive support group, he may find it more difficult to progress through treatment. An offender's motivation to change his behavior may be another obstacle in treatment. Because treatment is mandated, an offender may lack motivation to change his behavior or he may not think his behavior is problematic enough to change. Combined, if offenders lack social support and have low motivation to change their behavior, these may be obstacles to successful advancement through treatment.

\section{$\underline{\text { Sexual Offending and Offender Characteristics }}$}

Sexual assault is characterized as unwanted sexual touch by another individual or any type of sexual act without an individual's consent. Sexual assault can include a variety of unwanted sexual activities, such as rape (attempted or completed), unwanted oral or anal sexual acts, child molestation, and incest. Examples of individuals who may not be able to provide consent include anyone who is unconscious, under the influence of alcohol or drugs, forced into sexual activity, developmentally disabled, or under the age of 18 (The National Center for Victims of Crime, 2008). 
Male offenders charged with sexual assault (i.e., forcible rape, sodomy, sexual assault with an object, and forcible fondling) reported to law enforcement make up $96 \%$ of all offenders (Snyder, 2000). Seventy-seven percent of all offenders are adults and $23 \%$ are juveniles at the time they offended. Approximately $27 \%$ of all offenders are related to their victims, $60 \%$ are acquaintances of the victims, and $14 \%$ are strangers (Snyder, 2000).

\section{Policies and Treatment for Sexual Offenders}

\section{Treatment in Prison}

There are approximately 300,000 sex offenders in the prison system; however, only 480 therapists nationwide are treating this population (as cited in Heil \& English, 2007). Sex offender treatment in prisons typically lasts between 6 and 48 months. The National Institute of Corrections (NIC) uses evidence-based principles for treatment (as cited in Heil \& English, 2007). According to the NIC, treatment programs should assess offender risk and needs levels to determine static and dynamic risk factors. Static risk factors cannot be changed and are part of a criminal's history (e.g., criminal offense history). Dynamic risk factors can be changed over the course of time (e.g., hostility toward women). Treatment teams should motivate the offenders to change their behavior, and upon release into the community, offenders should be placed around positive support groups to help deter from re-offense (as cited in Heil \& English, 2007).

\section{Megan's Law}

After serving a prison sentence, offenders released into the community are required by law to be added to a registry list by the state (Jacob Wetterling Crimes 
Against Children and Sexually Violent Offender Registrations Act, 1994; National Alert Registry, n.d.). The law requires states to create registries of offenders who commit sexual offenses in order to track the offenders; all offenders must provide their place of residence. The law was passed in 1989 after an 11 year old boy in Minnesota was kidnapped by a sexual offender. Years later, a young girl by the name of Megan Kanka was murdered by a known sex offender. Shortly after Megan's murder, policy makers amended the previous law so that sex offenders could also be monitored by the public in addition to just state authorities. This new law was passed in 1996 and is known as Megan's Law (National Alert Registry, n.d). This law disseminates information from the registries to online public registries. Each state has an online sex offender public registry website viewable by the public. In an effort to allow parents to protect their children, the registries include information regarding where a sex offender lives, and the crime committed (Levenson, D'Amora, \& Hern, 2007). Currently, there are 374,270 registered sex offenders in the United States (National Alert Registry, n.d.).

$\underline{\text { Recidivism }}$

Recidivism is the re-offense of a crime and it can refer to any type of criminal offense. Sex offenders are actually less likely to re-offend and commit a new sex crime compared to non-sex offenders (Langan, Schmitt, \& Durose, 2003; Bureau of Justice Statistics, 2003). Literature on the effectiveness of Megan's Law to reduce recidivism rates is mixed. (Levenson et al., 2007; Duwe \& Donnay, 2008). A time-series analysis was conducted before and after the registration and notification laws were implemented and found no effect on the rates of sexual offending (Sandler, Freeman, \& Socia, 2008). 
Similarly, Bonnar-Kidd (2010) notes that laws passed to reduce recidivism within the last 15 years show little impact on recidivism rates and on the incidences of crimes related to sexual activity.

\section{$\underline{\text { Civil Commitment }}$}

Policy makers have developed civil commitment laws that require the detainment of the most violent of sexual predators (Zonana, 1997). The laws first appeared in the 1930s and many states passed what they called "sexual psychopath laws." These laws provided treatment and hospitalization in place of incarceration for offenders who repeatedly engaged in sexual offenses. The treatment provided during this time period was found to be ineffective and the laws soon ceased to exist. As a result of ineffective treatment, offenders were given longer sentences. However, they could be given earlier release dates if parole boards approved, and they were seen as safe enough to reintegrate into the community. This time period is called "indeterminate sentencing." The former time period was then replaced with a period of determinate sentencing. Offenders were then given a sentence that was based on the average length of time offenders spent in jail during the indeterminate sentencing period. The problem with determinate sentencing is that some offenders were still unstable at the end of their sentence, but were still released. As a result, many of these offenders reoffended (Zonana, 1997).

Recidivism rates did not drop as a result of determinant sentencing, and it was not until 1980 when a new form of civil commitment was put into effect. This new form required that sexual offenders, deemed more likely than not to reoffend, be detained until completion of an intense treatment program. Washington was the first state to implement 
new sex offender laws, which stated that if offenders were deemed dangerous and had a mental abnormality, then they could be civilly committed (Miller, 2010). Each state has similar, but different processes, to determine if an offender poses a danger to the community.

In Iowa for instance, code $229 \mathrm{~A}$ states that there is a small portion of sexual offenders who pose great harm to the community and are referred to as sexually violent predators. These individuals are found to have anti-social personality disorder that cannot be treated in therapy. This is not to be confused with a mental disorder that would prevent offenders from understanding treatment. Anti-social personality disorder constitutes an inability to control sexually violent behavior; therefore, the likelihood to engage in a sexually violent offense increases. An offender who appears to meet the criteria for a sexually violent predator, as determined by the jurisdiction where the offender resides, is subject to civil commitment. At least ninety days prior to the offender's discharge, the jurisdiction gives written notice to the attorney general and a multidisciplinary team. The multidisciplinary team includes individuals from within state agencies and outside of state agencies to review the offender's records. Within thirty days, the team determines if the offender meets the criteria for a sexually violent predator and if so, the attorney general is notified. The attorney general then files a petition to the court and the court requires that the offender is served with the petition and taken into custody. Three days after being taken into custody, a hearing is held where the court decides if there is probable cause the offender is a sexually violent predator. If probable causes exists, the offender is civilly committed (Sexually Violent Predator Act, 1998). 
Since the 1980s, a total of 20 states and the federal government have adopted civil commitment laws. Civil commitment requires that the most violent sexual offenders continue to be confined because they are deemed likely to reoffend (Zonana, 1997).

Treatment during civil confinement. Civil commitment provides long term treatment in highly structured environments for the treatment of sexually violent predators. More than 4,500 offenders have been confined since 2006 (Gookin, 2007). Twenty states have adopted civil commitment laws and provide different forms of treatment. In Iowa, for example, offenders have to go through a five-phase treatment program. Each phase of treatment includes group and individual therapy, educational programming for those who do not have the skills needed to participate in treatment, physiological assessments (i.e., plethysmograph), and strategies to prevent relapse (Titus, nd). Civil commitment treatment programs across the country are similar to one another; however some treatment requirements may differ. For example, Texas has a five-stage treatment program in which a polygraph is used at each stage. However, some states do not require polygraphs to be given during each stage. During the first stage, offenders must take on responsibility for their actions and learn how to control their anger. The second stage requires the offenders to talk about their sexual histories and then take a polygraph to determine the accuracy of their histories. The third stage requires that the offenders go through the cycle of the events leading up to the offense (e.g., their feelings and plans) and then they have to take another polygraph. Stage four discusses relationship issues and a penile plethysmograph is used to determine the offender's sexual preferences. Finally, stage five discusses relapse prevention and prepares the 
offender for integration into the community (Meyer, Molett, Richards, Arnold \& Latham, 2003).

Opponents of civil commitment question the effectiveness of treatment in the rehabilitation units. Some argue that offender confidentiality in these units is not protected because offenders are required to discuss their sexual fantasies (Miller, 2010). Sexual fantasies and behavior have been found to be linked together. Thirty eight percent of individuals who reported having a sexually deviant fantasy also acted out their deviant fantasy (Williams, Cooper, Howell, Yuille, \& Paulhus, 2009). In civil commitment treatment, after an offender discusses the sexual fantasies those stories can be used against the offender, which can be used as a reason for further confinement. This may cause the offenders to withhold information for fear it will be used against him; however, if the offender withholds or does not participate in treatment then therapists are not able to document progress in treatment. This can lead to an offender's extended stay.

Although the effectiveness of treatment may be in question, civil commitment prevents sexually violent offenders from posing harm to the community by virtue of their being indefinitely detained (Miller, 2010).

\section{Obstacles to Positive Treatment Outcomes}

\section{$\underline{\text { Self-Defeating Behaviors }}$}

Self-defeating behavior refers to those behaviors that cause self-harm. The behavior may be intentional or unintentional, but regardless, ends up defeating ones overall goals (e.g., to progress through treatment in order to be released; Curtis, 1989). Most commonly, an individual will engage in a behavior that will create short term 
benefits at long term cost (Baumeister \& Scher, 1988). Short term benefits and long term costs are related to procrastination in students. Students who procrastinate early on in the semester are less stressed compared to students who start on projects right away. However, procrastinators report feeling adverse effects (e.g., more illness) later on in the semester that exceed the adverse effects felt by the non-procrastinators. Overall, procrastination led to a decrease in performance on schoolwork (Tice \& Baumeister, 1997).

The term self-defeating can be used broadly and encompasses a variety of behaviors. For example, self-handicapping is a self-defeating behavior in which an individual purposefully engages in a negative behavior to protect the individual's selfesteem. For example, a person may purposefully not study for a test, which will likely result in poor performance. However, the person's self-esteem is less likely to be affected because they attribute the poor performance on not studying rather than attributing it to their intelligence. This is self-defeating because the person performed poorly on the test by not studying (Curtis, 1989).

Individuals who purposefully engage in a negative behavior are not the only people subject to self-defeating behaviors. People who feel left out may wind up feeling defeating. For example, offenders who have been civilly committed after completion of their prison sentence may feel out of touch with individuals they were close to prior to their incarceration and commitment. As a result, people who feel their actual level of belonging does not live up to their desired level of belonging are more likely to exhibit interpersonally harmful behaviors and less helpful behaviors (e.g., are less likely to 
volunteer to do things for the team; Thau, Aquino, \& Poortvliet, 2007). In populations such as prison and civil commitment units, offenders may have a desired level of belonging that does not meet their actual level of belonging. As a result, they may be more likely to engage in self-defeating behaviors.

In civil commitment units, behaviors of sex offenders that are amenable to change through the process of treatment are termed "dynamic risk factors." These risk factors include aspects of the offender's thoughts and behaviors and are used to monitor their progress in treatment. An example of such thoughts and behaviors are the level of acceptance of guilt for the offense and the level of participation in treatment (Witt \& Schneider, 2005). If an offender does not participate in treatment as expected by the treatment center, or chooses to only participate in treatment on certain days, then this would be considered a self-defeating behavior. Although these behaviors are amenable to change throughout the treatment process, offenders often have thoughts and engage in behaviors that are self-defeating and inhibit their progress in treatment. A previous study proposed that individuals have innate self-destructive tendencies, especially when they feel guilty or distressed (Twenge, Catanese, \& Baumeister, 2002). In civil commitment treatment facilities, treatment requires offenders to disclose their offenses and relive the crime. This may cause offenders to feel guilty about their actions, which may cause them to have self-destructive tendencies. Understanding self-defeating behaviors and factors that play a role in these behaviors is important in the treatment process. 


\section{Protective Factors for Treatment Success}

\section{Social Support Systems}

Social support is related to self-defeating behavior. People may engage in selfdefeating behaviors when they are socially isolated and also when they anticipate social isolation later in life. People who are told they will be socially isolated later in life may also take foolish risks. For example, Twenge et al. (2002) found that individuals who were told they would be socially isolated later in life made more risky choices than individuals who were told they would have rewarding relationships for the rest of their life. Individuals in the social isolation group also engaged in less healthy behaviors compared to individuals in the rewarding relationships group (e.g., choosing to eat a candy bar instead of a granola bar). People were also more likely to procrastinate on studying for a test in the socially isolated group. These examples indicate that the perceived notion of social isolation results in poor outcomes.

Social support systems are an important aspect of everyday human life. Social support is the "perceived or actual instrumental and/or expressive provisions supplied by the community, social networks, and confiding partners" (Lin, Dean, \& Ensel, 1986, p. 18). Social support can be real or imagined and is derived from constraints and opportunities based on experiences individuals have throughout their life. Having a sense of social support (called perceived social support) creates a sense of self and a sense of others. This sense of self and others creates a self-identity that is important for an individual when understanding relationships and the expectations of those relationships (Sarason, Pierce, Shearin, Sarason, \& Waltz, 1991). These social networks impact the 
way individuals approach crisis situations, and social support systems may influence how one strategizes in certain situations (e.g., treatment; Gutierrez-Lobos et al., 2001). Perceived social support is not only relevant when an individual is in a crisis, but the social support drives an individual's social behavior (Sarason et al., 1991). People who are rejected lose their self-regulation and their level of intelligent thought is decreased (Baumeister, Brewer, Tice, \& Twenge, 2007). Overall, social support systems promote both physical and psychological health (Sarason, Sarason, Shearin, \& Pierce, 1987; Jacoby \& Kozie-Peak, 1997; Cutrona \& Russell, 1987).

In addition to perceived feelings of social isolation later in life, lower feelings of social support bring about stress due to public notification laws. Offenders have lower feelings of social support in regard to Megan's law allowing public notification of sexual offenders; this contributes to their feelings of isolation. Offenders have reported that the law makes them stressed, feel isolated, ashamed, embarrassed, hopeless, and disrupts their social relationships (Levenson et al., 2007). For example, sexual offenders in Florida are subject to public notification for life (Florida Department of Law Enforcement, 2007). Out of a sample of 183 sex offenders in Florida, 15\% reported losing a job because their boss found out they were a sex offender and $18 \%$ reported having been threatened by neighbors. However, $18 \%$ of offenders noted the law makes them feel more motivated and less likely to recidivate because they want to prove they are a good person. Although motivation increased for some offenders, others (27\%) did not feel a need to change because people assumed they could not (Levenson \& Cotter, 2005). 
In prison populations, social support during the sentence and after release has been shown to provide a higher quality of life after release. Individuals who reported having more social support while they were in prison were less likely to end up in a shelter and have fewer problems associated with daily living after their release (e.g., offenders were more satisfied financial and health status). Also, the more social support individuals had while they were in prison, the more contact they had with friends and family after their release (Jacoby \& Kozie-Peak, 1997). According to Sarason, Levine, Basham, and Sarason (1983), people who have high social support systems seem to view life more optimistically and have positive self-concepts, whereas people with low social support systems are dissatisfied with life.

\section{Motivation to Change}

A crucial issue in the treatment of sex offenders is the offender's motivation to change his behavior (Tierney \& McCabe, 2004). It is the role of mental health professionals to treat offenders in order to reduce the likelihood of re-offending; however, treatment is just one aspect in the process of change. Offenders have to want to change and they indicate this by engaging in treatment and practicing what they are taught (McMurran, 2002). Before an offender can change his behavior, he has to have sufficient motivation to fully participate in treatment. More often than not, in general, people will not engage in behaviors unless they are motivated to do so (DiClemente, Bellino, \& Neavins, 1999).

Motivation to change over time can be categorized into distinct sequences also known as the stages-of-change model (McConnaughy, Prochaska, \& Velicer, 1983). The 
stages-of-change model is made up of 5 stages. The first stage is the pre-contemplation stage. In this initial stage, clients deny having a problem or do not want to change. Clients in this stage may not be in treatment for their own benefit, but rather for others (pressure from family, or court ordered). The second stage is the contemplation stage where clients have first insight of the problem they are facing. They may not actually be aware there is a problem, but may understand that something is bothering them and they seek to find out more about the problem. The third stage of change is decision making. People have taken responsibility of their problem and want to change, yet have not started working toward the change. They understand that they may have to put forth time and effort in their process toward change. The fourth stage of change is the action stage where clients have actively started to change their problematic behavior. Some people in this stage may be struggling with their change and need help. The last and final stage of change is maintenance. Clients in this stage have made changes to their behavior or environment, but may slip back into their old ways and need help with strategies to prevent relapse. Motivation is a key element in treatment and can influence progress in the stages of change (DiClemente et al., 1999).

A scale was developed using the stages-of-change model to determine attitudes representing each of the stages of change: The University of Rhode Island Change Assessment Scale (URICA; DiClemente \& Hughes, 1990). The scale was developed using a sample of individuals struggling with substance abuse. The goal of the study was to determine distinct profiles of individuals regarding the stages of change. Cluster analysis was used to determine the distinct profiles and yielded five clusters: Pre- 
contemplation Cluster, Ambivalent Cluster, Participation Cluster, Uninvolved or Discouraged Cluster, and Contemplation Cluster. Individuals in the Pre-contemplation Cluster did not plan on changing their behavior and preferred to maintain their current status of behavior. Ambivalent Cluster individuals are apprehensive about whether to change problematic behaviors and are in conflict with staying the same or progressing toward change. The Participation Cluster was ready to change their behaviors and had invested in making this happen. The Uninvolved or Discourage Cluster were uninvolved in changing behaviors and were likely to have lost hope in changing. The Contemplation Cluster individuals were optimistic about changing at some point; however, no action had been taken to bring about change (DiClemente \& Hughes, 1990). These clusters have been used in clinical populations to determine individuals' stages of change. Depending on the stage of change, treatment can be tailored to target the various stages of change and move them along.

Motivation and treatment. Motivation and treatment efficacy with a group of incarcerated offenders was examined following a cognitive-behavior treatment program to reduce cognitive distortions in offenders. Out of a total of 31 offenders, 11 were motivated to do treatment and succeeded; however, similar findings were noted for the un-motivated offenders (11 of these offenders also succeeded). The study concluded that motivation had no significant effect between the two groups in the reduction of cognitive distortions. However, the study did find that offenders who victimized adults may benefit from cognitive-behavioral treatment even if they are not motivated to participate (Terry \& Mitchell, 2001). 
Barrett, Wilson, and Long (2003) measured motivation to change in 101 federally sentenced sexual offenders over four stages of treatment processes: institutional assessment, following institutional treatment, upon conditional release to the community, and following a 12-week period of community treatment. The offenders were split into three groups according to their offense (i.e., pedophiles, non-pedophilic child molesters, and sexual aggressive (rapists). Individuals in all three groups had equal levels of motivation to change at the institutional assessment stage. Results showed that in community treatment, acceptance of responsibility and accepting guilt indicated positive treatment outcomes. Motivation to change and participation in treatment yielded significance at the community treatment level. This study indicates that motivation to change can increase with time and across treatment levels.

Overall, social support and perceived isolation in the future has been linked to self-defeating behaviors. In treatment contexts, motivation to change behavior is critical for treatment success. In civil commitment units, the completion of treatment is required before a civil court can grant approval for an offender to be reintegrated into the community. Therefore, defeating one's self by not following the guidelines of treatment can prolong the treatment process and eventual release. The goal of the current study was to determine if perceived social support and level of motivation to change are related to perceived self-defeating behaviors and offender's self-defeating behaviors as rated by his therapist. 


\section{CHAPTER 2}

\section{THE PRESENT STUDY}

The present study sought to determine whether social support and motivation to change in civilly committed sexual offenders impacted self-defeating behaviors.

\section{Statement of Purpose}

The present study will add to the literature by:

1. determining if the level of social support and motivation to change impact treatment progression,

2. determining if the level of social support and motivation to change decrease self-defeating behaviors, and

3. determining if more social support and higher levels of motivation to change serve as a protective factors and result in fewer self-defeating behaviors.

\section{$\underline{\text { Hypotheses }}$}

It is hypothesized that:

1. Hypothesis 1: Offenders with less social support and less motivation to change will be in a lower phase level ( 5 total phases; phase $5=$ prior to release into the community) of treatment compared to offenders with more social support and more motivation to change.

2. Hypothesis 2: Offenders with more social support and more motivation to change will engage in fewer self-defeating behaviors compared to offenders with less social support and less motivation to change. 
3. Hypothesis 3: Offenders with less social support and less motivation to change will take longer to progress through treatment over time compared to offenders with more social support and more motivation to change.

4. Hypothesis 4: Offenders who have been in treatment longer will endorse higher scores in the maintenance phase compared to the pre-contemplation, contemplation, and action phases.

5. Hypothesis 5: More phase penalties over the course of treatment will be negatively correlated with more social support and higher levels of motivation to change.

\section{Method}

\section{Choice of Facility}

The Civil Commitment Unit for Sex Offenders (CCUSO) is the only civil commitment unit in the state of Iowa. A proposal was sent to CCUSO and the Iowa Attorney General requesting permission to conduct research at CCUSO. The proposal was reviewed and permission granted upon approval from the University of Northern Iowa's Institutional Review Board (IRB). The IRB requested a full board review of the study before permission was granted. The IRB requested all identifying information during data collection be destroyed as a cautionary procedure if subpoenaed by the courts. In this case, no identifying information could be matched to any participants, which could have resulted in a breach of confidentiality. 


\section{Participants}

Seventy-four adult male sex offenders were recruited through the Civil Commitment Unit for Sex Offenders in Cherokee, Iowa (CCUSO). The offenders completed their prison sentences, but in a separate civil trial met the criteria for high risk recidivism (i.e., likelihood to commit further violent sexual offenses), and are being detained indefinitely. CCUSO refers to the offenders as "patients" and will be referred in this paper as "offenders" and "patients."

Offender ages were collected in ranges to protect anonymity; therefore, ages ranged from $18-66+$. The majority of offenders identified as Caucasian (68\%) and African-American (18\%); fewer identified with Native American/Indian (8\%), other (7\%), Multiracial (5\%), and Hispanic/Latino (3\%). Approximately $18 \%$ of offenders reported they have been convicted of offending against children 0-5 years of age. Fiftyeight percent reported having been convicted of offending against 6-12 year olds, $47 \%$ have been convicted of offending against $13-15$ year olds, $30 \%$ have been convicted of offending against $16-17$ year olds, and $47 \%$ have been convicted of offending against adults 18 years of age and older.

\section{$\underline{\text { Measures }}$}

Demographics questionnaire. A questionnaire was administered to obtain demographic information from respondents including age, marital status, marital history, and number of children they have (see Appendix A).

Social support. The Source-Specific Social Provisions Scale was modified from The Social Provisions Scale, which measures the provisions of social relationships 
(Cutrona, 1989). The provisions include: guidance (advice or information), reliable alliance (assurance that others can be counted on in times of stress), reassurance of worth (recognition of one's competence), attachment (emotional closeness), social integration (a sense of belonging to a group of friends), and opportunity for nurturance (providing assistance to others). The Source-Specific-Social Provisions Scale provides information regarding which people (e.g., family, significant other) provide the provisions of the social relationship. The scale is made up of three sections. Each section has the same 12items, the difference being the source (i.e., friends, parents, and partner) from which the respondent is supposed to tailor their answers. The source-specific total score correlated $.65(d f=109, p<.001)$ with the original Social Provisions Scale (Cutrona, 1989; see Appendix B). The correlations for the source-specific subscales with the Social Provisions Scale were .44 (parent), .56 (friend), and .31 (male partner).

For purposes of the study, "parent" was changed to "family" as some of the participants may no longer have parents, and "male partner" was changed to "partner" due to the characteristics of the sample (i.e., all participants were male).

Motivation to change. McConnaughy and colleagues (1983) developed a scale that measures the stages of motivation to change: Pre-contemplation, Contemplation, Action, Preparation, and Maintenance. However, due to poor statistical qualities in the Preparation stage (i.e., nine out of the ten original items in this stage loaded into the contemplation and action factors), the Preparation stage was eliminated (McConnaughy et al., 1983). Eight items out of the total 32 items load into one of the four stages of change (possible range $=8-40 ;$ McConnaughy et al., 1983). Internal consistency 
reliability coefficients were determined for each of the scales: Pre-contemplation (.88), Contemplation (.88), Action (.89), and Maintenance (.88). (McConnaughy et al., 1983).

The University of Rhode Island Change Assessment Scale (URICA; DiClemente \& Hughes, 1990) was developed to measure a person's motivation to change a maladaptive behavior and is based off of the four stages of change developed by McConnaughy and colleagues (1983; see Appendix C). The URICA contains 32 selfreport items and responses are given on a 5-point Likert scale ranging from 1-strong disagreement to 5-strong agreement. To determine scoring on the URICA, total scores are summed from the items on each subscale (Pre-Contemplation, Contemplation, Action, and Maintenance; Likert scale ranging from 1-5). Four items were excluded (e.g., one item from each of the four subscales) due to weak loadings and the resulting total scale score ranged from 7-35; the higher the score the more individuals endorsed items on that particular subscale. A total readiness score can be calculated by taking the sum of the Contemplation, Action, and Maintenance subscales and subtracting the summed scores from the Pre-Contemplation subscale (score range -2 to +14 with higher scores indicating greater readiness to change; DiClemente \& Hughes, 1990). Using the new format of the scale, Cronbach's Alpha was calculated for each of the four stages: Pre-contemplation (.69), Contemplation (.75), Action (.82), and Maintenance (.80).

For purposes of the current study, the original subscales developed by McConnaughy et al., 1983 were used due to higher Cronbach's Alphas for the original items, and the total readiness score was calculated using DiClemente and Hughes (1990) revised subscale format with the excluded items (score range -2 to +14 ). 
Social desirability. The Social Desirability Scale created by Crowne and Marlowe (1960) determines the likely truthfulness of participant's responses. The scale consists of 33 true and false items (e.g., I have never deliberately said something that hurt someone's feelings), which are culturally approved, but are impossible to escape (Crowne \& Marlowe, 1960). Individuals who answer many items in the keyed direction are assumed to be attempting to project a favorable image of them. Consequently, participants scoring high in the Social Desirability Scale may be attempting to appear overly virtuous and may not be responding to other questionnaires truthfully. The internal consistency coefficients range from .72 to .88 with a test-retest reliability coefficient of .89 (see Appendix D).

Self-defeating behaviors. An 8-item questionnaire was developed to determine self-defeating behaviors. Questions are rated on a 1-5 Likert scale (See Appendix E). Examples of questions include: "in the last 90-days, to what degree have you found it difficult to get along well with others," and "how motivated are you to successfully complete treatment and be released?"

\section{$\underline{\text { Archival Data }}$}

This study used archival data from CCUSO consisting of treatment program outcome measures. All files were analyzed for content (discussed in the next paragraph) on each offender and all records used were de-identified after they were matched to the offender's respective questionnaires; therefore, no specific file could be linked back to any individual offender after analysis. File contents included: current phase, time in 
current phase, length of commitment, and 90-day evaluations completed by a therapist every 90 days.

90-day evaluations. Every ninety days from the date of admission, patients are given a written review of progress in the program. The 90-day evaluations are determined by an evaluation from a psychologist in the rehabilitation center. The evaluations were collected from archives dating back to March 2004. Many offender evaluations dated prior to March 2004 were not available; therefore, this date was used as a cut-off. A total of 1,291 evaluations were collected. There are three parts to the evaluation: scores derived from two risk assessments and the offender's score in ten treatment areas (described in the following paragraphs). The form used for archival data collection included these three areas, as well as the offender's age range, length of commitment, current and previous phases, and the time length in each of the phases (see Appendix F).

Stable. The Stable is used to assess stable, dynamic predictors of re-offense in sexual offenders (Hanson, Harris, Scott, \& Helmus, 2007). Stable risk factors are factors that change slowly or may not even change at all. It consists of 13 "Basic Concepts" and these concepts are determined by a direct interview or file review of the risk factors in sex offenders. Some of the concepts include: Significant Social Influences, Capacity for Stable Relationships, and Emotional ID with Children. The Stable is designed to identify recidivism risk of offenders who are in the community on probation and parole (Hanson et al., 2007). Because the Stable is traditionally designed for offenders in the community and not for detained offenders, therapists at CCUSO do not administer the measure in its 
totality. Traditionally, offenders are given a thorough interview and required to answer several questions. However, therapists at CCUSO do not administer the formal interview, but rather, use it as more of a guideline to target problematic dynamic behaviors. (M. Ryan, personal communication, June, 2011). The original scoring on the Stable ranges from $0-2$ for each of the 13 basic concepts previously mentioned with 0 indicating no problem and 2 indicating a definite problem. Instead of using 0 through 2 as scores, offenders who have problematic risk factors are given an " $\mathrm{x}$ " by their therapist indicating it was a problem. For purposes of this study, the " $x$ " was scored as a " 1 ", and if the area was not problematic for an offender (i.e., there was not an " $x$ " next to a risk factor), the risk factor was scored as a "0'. Two items on the Stable (i.e., Significant Social Influences and Cooperation in Treatment) are written out by the therapist. Significant social influences refer to positive and negative social influences the offender has and cooperation in treatment refers to the offender's degree of cooperation in supervision. Significant social influences was coded as either a "1" (has positive social influences) or a "0" (does not have positive social influences). Cooperation in treatment was coded as " 0 " (does not cooperate in treatment), " 1 " (some difficulty cooperating in treatment), and "2" (cooperates in treatment). Total scores on this measure range from 0-13; higher scores indicate less self-defeating behaviors.

Acute. The Acute is used to assess dynamic predictors of re-offense in sexual offenders. It consists of seven factors: Victim Access, Hostility, Sexual Pre-Occupation, Emotional Collapse, Rejection of Supervision, Substance Abuse, and Collapse of Social Support. Acute factors change rapidly over a period of weeks, days, or minutes (Hanson 
et al., 2007). A "unique factor" can be added to the original seven factors for offenders who display a problematic area aside from the other factors. The unique factor is different for every offender. For example, an offender who displays anger during treatment groups may have a unique factor of "anger management," and an offender who does not comply with women staff members may have a unique factor of "hostility toward women." Offenders can have more than one unique factor. Scores for each item on this measure range from 0-2 with 2 indicating more problems. Similar to the Stable, the Acute is not administered, but the dynamic risk factors the offender is having a problem with are documented in their 90-day evaluations.

Ten treatment areas. The 10 treatment areas are used as a guide by the therapist to rate an offender's level of progress in treatment. The 10 areas include: disclosure, insight, personal victimization, empathy, health/hygiene/leisure skills, cognitive coping strategies, sexual behaviors, relapse prevention, intimacy skills, and problem solving. In each of the treatment areas, offenders have to demonstrate verbally what each treatment area means and then write up a statement that he understands what the areas mean. After the offender has articulated and written his statement of understanding, he is then given a score. The following information provides a detailed synopsis of the ten treatment areas. Offenders are given a score by their therapist ranging from $0-8$ on each area. This score was recorded on the record review form (see Appendix F).

Disclosure. Disclosure is the degree to which the offender has thoroughly disclosed his sexual behavior and offense history. The purpose of disclosure is for the offender to completely and accurately identify all entrenched deviant sexual preferences 
and state dependent arousal, which can in turn be used to determine the function of the sexually deviant behavior and target specific therapeutic interventions.

Insight. Insight is the degree to which the offender has shown insight into the various social, behavioral, emotional, and cognitive factors that contributed to his offending behavior, and recognizes his vulnerabilities and his cycle of abuse. By understanding the social/cultural and cognitive factors that contributed to offending an individual can recognize current and potential factors that set the occasion for offending and use appropriate interventions to not reoffend.

Personal victimization. Personal victimization is the degree to which the offender appears to have resolved past traumas, resentments, and other forms of personal victimization. Resolution of past traumas is assumed to be arguably related to selfesteem and therefore, will need to be addressed so an individual has the ability to achieve life's important goals.

Empathy. Empathy is the degree to which the offender shows empathy, remorse, and an understanding of the impact of his sexual offending and accepts full responsibility for his behavior. The purpose of empathy is to address cognitive distortions about the needs of other people and develop a distinction between the need for intimacy and seeking sexual satisfaction at another person's expense.

Health, hygiene, and leisure skills. Health, hygiene, and leisure skills are the degree to which the offender has demonstrated acceptable health and hygiene practices and developed meaningful personal goals, leisure skills, and activities that will meet his 
existential needs. The purpose of this area is to develop a positive self-identity and develop a sense of excellence in work and play activities.

Cognitive coping skills. Cognitive coping skills are the degree to which the offender demonstrates good internal cognitive coping skills, anger management, and had reduced cognitive distortions. Cognitive coping skills allow the offender to address the presence of cognitions justifying sexual aggression, which can be linked to a lack of knowledge or too narrow of focus. It is also related to emotional regulation and the tendency to justify sexual deviancy as a means to cope with negative moods.

$\underline{\text { Sexual behaviors. Sexual behaviors are the degree to which the offender has }}$ recognized and altered his dysfunctional sexual behaviors and beliefs. The purpose of this area is to address the presence of deviant sexual arousal related to the individual's interest in either children or coercive sex, or other abnormal sexual activity, which may reflect entrenched deviant sexual preferences, or more state-dependent arousal.

Relapse prevention. Relapse prevention is the degree to which the offender has developed a comprehensive relapse prevention plan. The purpose is to thoroughly develop the pattern of social/cultural, environmental, emotional, and cognitive factors that lead to sexual offending and identify general and contextual interventions that reduce the likelihood of offending.

Intimacy skills. Intimacy skills are the degree to which the offender has demonstrated good relationships and intimacy skills. The purpose is to address the tendency to blur the distinction between intimacy (relatedness) and sexual satisfaction, as well as difficulties with control issues and self-esteem. 
Problem solving skills. Problem solving skills are the degree to which the offender has demonstrated good communication and problem solving skills. The purpose is to address emotional regulation and cognitive distortions that result in ineffective or absence of skills.

Phases of treatment. After each offender is given a score on the 10 treatment areas by his therapist, he is placed in one of five treatment phases (i.e., current phase; see Appendix F). For the current study, progress in treatment was determined by averaging the length of time offenders have been in a phase. For example, if an offender was in phase 4 for three months then moved down a phase to phase 3 for six months, and moved back to phase 4 for five months, the amount of time (months) was summed and divided by the total number of phases they have been in during commitment. Therefore, fourteen months was divided by two because the offender was in two phases even though he was in phase 4 twice. The rationale for defining progress in treatment in this manner is even though the offender was in phase 4 twice, they received the same type of treatment in this phase. A penalty in phases of treatment would result in the loss of a phase. For example, an individual in phase 3 who violates the guidelines of his phase agreement and has to revert back to phase 2 would result in one penalty. The following information provides a description of the phases:

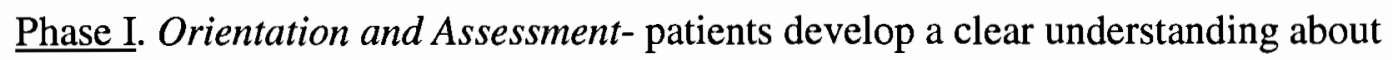
program expectations and rules and undergo complete psychological testing. In order to progress to the next phase, patients must admit to some sexual offense or have a "clean 
polygraph," complete relaxation and basic cognitive skills training, and demonstrate good behavior for 30 days.

Phase II. Core Phase- the goal of this phase is education. Patients complete four quarters of classes that teach concepts and skills to help patients control sexual impulses and be able to meet needs in prosocial ways. In order to progress to the next phase, patients must pass polygraph exams relating to sexual disorders, demonstrate good behavior for 90 days, and have no ratings (in each of the ten treatment areas) lower than 3 out of a possible 8 on their last review.

Phase III. Advanced Phase- the goal of this phase is successful application of basic principles and insights. Patients work on applying the principles and concepts learned in Phase II and on achieving the goals established in their individual treatment plan. In order to progress to the next phase, patients must pass "specific offense polygraphs" if requested, complete "Victim Sheets" and "Victim Letters," demonstrate good behavior for four months, and have no ratings (in each of the ten treatment areas) lower than 5 out of a possible 8 on their last review.

Phase IV. Honor Phase- the goal of this phase is maturation and refinement of skills in preparation for release. Patients are expected to demonstrate a high level of cooperation, insight, motivation, and application of previously taught principles, should model appropriate behavior for other patients and be able to facilitate as a leader during group discussions. To progress to the next phase, patients must complete a detailed relapse prevention plan, pass a polygraph exam relating to sexual behaviors, demonstrate 
good behavior for six months, and have no ratings (in each of the ten treatment areas) of less than 8 out of a possible 8 on their last review.

Phase V. Transition Phase- the goal of this phase is successful completion of transition from CCUSO to the community; promotion of phase five requires an order of the committing court. The first part of phase five requires the patient to live in the CCUSO secure apartment setting within the facility. Patients will gradually be given increasing opportunities to go on passes and live in progressively less restrictive settings with close monitoring and clinical assessment of progress. Having met the requirements for successful completion of the first part of phase five, patients must maintain housing in a halfway house or residential facility outside the CCUSO grounds for six months to one year without violating rules or their relapse prevention plan, successfully maintain employment, attend weekly support therapy groups and individual counseling, fulfill all requirements of the release contract for at least two years, and pass random physiological assessments requested by transitional counselors. Having met the requirements for successful completion for the second part of phase five, CCUSO staff will recommend release to the committing court. Final discharge from the program requires an order of the committing court.

\section{$\underline{\text { Procedure }}$}

Fliers were placed on a unit to provide information about the study a week prior to data collection (see Appendix G). Data collection occurred on five different units. Staff was given a written statement to read to the patients requesting their participation the day of data collection (see Appendix H) and the treatment facility's master control 
center made an announcement over the intercom informing the offenders of the study. Those who chose to attend heard a presentation about the purposes of the study (verbal presentation: see Appendix I). All participants received an informed consent form (see Appendix J), which was also verbally explained to the participants. The informed consent contained two separate sections for signatures; one for consent to participate in the study and the other for consent to access archival records. Participants who provided consent to participate in the study and consent to have their archival records used, or who only consented to participate without consenting to have their archival records accessed were given the survey packet. Individuals who did not wish to participate in the study were free to leave at any time. Included in the survey packet was a piece of paper where the offender was asked to write their name (see Appendix K). This name sheet was later used to match survey data with archival data. Also included in the survey packet was an additional measure used by a second researcher conducting a separate study. This was done to eliminate multiple administrations of the measures and was more convenient for the offenders. Therefore, the total length of time required to complete the questionnaires was approximately an hour. Research investigators were available to answer questions during data collection. Participants handed in their questionnaires to the researchers and received two five dollar activity punch tickets (one for consent to participate and one for consent to access archival records) as compensation for their time.

Offenders who missed out on the opportunity to participate (e.g., they forgot about it) were given another opportunity at a later date and the questionnaires were administered in the same fashion as stated previously. Offenders identified as having low 
intellectual intelligence were read the questionnaires; however, all were able to respond to the questions on their own.

Archival data collection began during the same week the first group of offenders was recruited. Files were accessed in a secure file room using the record review form over a period of several months (see Appendix F). Each offender file contained a binder of their criminal history and length of commitment. The length of commitment was recorded on the record review form. Data was also collected from computer files which contained 90-day evaluations, phase levels, and time in each of the phases. The staff at CCUSO was in the process of converting written files to electronic files; therefore, files were accessed from the file room and from a computer.

After all data were collected, it was matched to its correct archival file and given an identifiable code (e.g., ID\#10000) and the paper with the participant's name was shredded. Therefore, no identifying information can be linked from the archival to the collected data.

\section{Power Analysis}

To determine the appropriate sample size for the current study, data from a previous study using similar sample populations (e.g., sexual offenders) and instruments (e.g., motivation to change) were used to conduct power analyses using $\mathrm{G}^{*}$ Power 3.1.3 (Faul, Erdfelder, Lang, \& Buchner, 2007). Results indicated that for adequate statistical power of .80 and a moderate effect size of $.30,82$ participants would be necessary. 


\section{CHAPTER 3}

\section{RESULTS}

\section{Demographics}

Sixty percent of offenders indicated they were single, $4 \%$ were in a committed relationship, $3 \%$ were married, $34 \%$ were divorced, $1 \%$ was widowed, and $3 \%$ were separated. Eighteen percent of the offenders had at least one child $(M=1.79, S D=2.75)$. The majority of offenders $(80 \%)$ indicated having been in a sexual offender treatment program other than CCUSO (10\% inpatient, $14 \%$ outpatient, and $72 \%$ while in prison). Of the offenders who had been in sexual offender treatment in prison, $16 \%$ were in treatment at least twice.

Regarding offenders' history of probation and parole, $78 \%$ indicated having been on probation and $42 \%$ on parole. Thirty-five percent of offenders previously on probation indicated having no difficulties, and $5 \%$ reported having extreme difficulties. Of the offenders previously on parole, $12 \%$ reported having no difficulties compared to $5 \%$ who indicated having extreme difficulties. Length of commitment for all offenders ranged from 2-148 months $(M=73, S D=41.2)$. Almost half of the offenders were in phase 2 of the treatment process. Phase breakdown is as follows: phase $1(11 \%)$, phase 2 (46\%), phase $3(24 \%)$, phase $4(14 \%)$, and phase $5(5 \%)$. The average length of time offenders had been in their current phase was 26 months $(S D=26.19)$. A breakdown of demographics is noted in Table 1. 
Table 1

Demographics

\begin{tabular}{|c|c|c|c|}
\hline \multicolumn{2}{|l|}{ Race } & \multicolumn{2}{|l|}{ Number of Children } \\
\hline & $(\%)$ & & $(\%)$ \\
\hline African American & $18 \%$ & $\mathbf{0}$ & $41 \%$ \\
\hline Hispanic/Latino & $3 \%$ & $\mathbf{1}$ & $18 \%$ \\
\hline Caucasian & $68 \%$ & 2 & $10 \%$ \\
\hline Native American/Indian & $8 \%$ & 3 & $10 \%$ \\
\hline Multiracial & $5 \%$ & 4 & $5 \%$ \\
\hline Other & $7 \%$ & 5 & $1 \%$ \\
\hline & & 6 & $1 \%$ \\
\hline Marital Status & & 7 & $1 \%$ \\
\hline & $(\%)$ & 8 & $4 \%$ \\
\hline Single & $60 \%$ & 16 & $1 \%$ \\
\hline Committed Relationship & $4 \%$ & Missing (999) & $8 \%$ \\
\hline Married & $3 \%$ & & \\
\hline Divorced & $34 \%$ & Offender Age Range & \\
\hline Widowed & $1 \%$ & & $(\%)$ \\
\hline Separated & $3 \%$ & $26-32$ & $7 \%$ \\
\hline & & $33-40$ & $15 \%$ \\
\hline Education Level & & 41-50 & $28 \%$ \\
\hline & $(\%)$ & $51-65$ & $38 \%$ \\
\hline Elementary/Grammar & $16 \%$ & $66+$ & $7 \%$ \\
\hline School & & Missing (999) & $5 \%$ \\
\hline High School/Equivalent & $45 \%$ & & \\
\hline Technical/Vocational & $8 \%$ & & \\
\hline School & & & \\
\hline Some College & $27 \%$ & & \\
\hline Missing (999) & $3 \%$ & & \\
\hline
\end{tabular}

\section{Data Transformations}

University of Rhode Island Change Assessment Scale

Items from the URICA were computed to equal a total score on each of the four stages. A total readiness to change score was computed by taking the sum of scores from the Pre-Contemplation stage and subtracting it from the combined sum of scores from the Contemplation, Action, and Maintenance stages. 


\section{$\underline{\text { Source-Specific Social Provisions Scale }}$}

Items geared in the negative direction on the Source-Specific Social Provisions Scale were recoded so that higher scores would equal greater social support. Recoded items are indicated with an " $R$ " on the item response line (see Appendix B). Scores from each source (i.e., friends, family, and partner) were computed together to equal one total social support score.

\section{$\underline{\text { Stable and Acute }}$}

The Stable and Acute in the 90-day evaluations were recoded so that higher scores indicate less self-defeating behaviors. The ten treatment area scores on the 90-day evaluations were not recoded as higher scores indicate fewer problems in each of those areas resulting in less self-defeating behaviors.

\section{$\underline{\text { Self-Defeating Behavior Questionnaire }}$}

Specific items on the self-defeating behavior questionnaire were recoded so that higher scores indicate less self-defeating behaviors. This was done to be consistent with the scores on the 90-day evaluations. Recoded items are indicated with an "R" at the beginning of each item (see Appendix E).

\section{$\underline{\text { Missing Items }}$}

Missing items on all of the measures were accounted for during analyses and coded as "999." Out of the seventy-four most current 90-day evaluations that were collected, only two percent were unaccounted for. For the self-defeating questionnaire, approximately $11 \%$ of the 74 contained missing data. The Source-Specific Social Provisions Scale contained the most missing data as the offenders were told to skip the 
page if they did not have any friends, family, or romantic partner. The purpose being that it was not useful for an offender to answer questions regarding perceived social support if he did not receive support from one of the sources. As a result, $7 \%$ contained missing data from the friend source, $14 \%$ contained missing data from the family source, and $80 \%$ contained missing data from the partner source. For the URICA, less than $1 \%$ of the data was missing (5 items out of a total 2, 368 items).

\section{$\underline{\text { Social Desirability }}$}

The Marlowe-Crowne Social Desirability scale was used to determine the likely truthfulness of responses. The scale was correlated to each of the self-report measures to determine desirability in responses (Table 2). Higher scores on the Marlowe-Crowne Social Desirability scale indicate less social desirability. Means and standard deviations for the three scales are found in Table 3.

Table 2

Correlations Between Social Desirability and Self-Report Questionnaires

\begin{tabular}{|c|c|}
\hline & $\begin{array}{c}\text { Social } \\
\text { Desirability } \\
r \\
\end{array}$ \\
\hline $\begin{array}{l}\text { Self-Defeating } \\
\text { Questionnaire }\end{array}$ & .027 \\
\hline URICA & $.234 *$ \\
\hline $\begin{array}{l}\text { Source-Specific } \\
\text { Social } \\
\text { Provisions Scale }\end{array}$ & -117 \\
\hline
\end{tabular}


Table 3

Means and Standard Deviations for the Self-Defeating Questionnaire, URICA, SourceSpecific Social Provisions Scale, and Social Desirability Scale

\begin{tabular}{lccc}
\hline & $M$ & $S D$ & $\begin{array}{c}\text { Possible } \\
\text { Range of } \\
\text { Scores }\end{array}$ \\
\hline Self-defeating questionnaire & 30.47 & 6.10 & $8-40$ \\
URICA & 9.60 & 2.10 & $32-160$ \\
Source-Specific & 62.42 & 18.50 & $36-108$ \\
Social Desirability & 49.51 & 6.16 & $33-66$ \\
\hline
\end{tabular}

Hypotheses

$\underline{\text { Hypothesis } 1}$

Offenders with less social support and less motivation to change will be in a lower phase level of treatment compared to offenders with more social support and more motivation to change

Intercorrelations and Cronbach's Alpha were determined for the subscales on the URICA (Table 4) and the Source-Specific Social Provisions Scale (Table 5). 
Table 4

Intercorrelations Between Subscales and Total Readiness on the University of Rhode Island Change Assessment Scale

\begin{tabular}{|c|c|c|c|c|c|}
\hline & $\begin{array}{c}\text { Pre- } \\
\text { Contemplation } \\
N=8\end{array}$ & $\begin{array}{c}\text { Contemplation } \\
N=8\end{array}$ & $\begin{array}{c}\text { Action } \\
N=8\end{array}$ & $\begin{array}{c}\text { Maintenance } \\
\qquad N=8\end{array}$ & $\begin{array}{c}\text { Total } \\
\text { Readiness } \\
\mathbf{N}=\mathbf{3 2} \\
\end{array}$ \\
\hline $\begin{array}{l}\text { Pre- } \\
\text { Contemplation } \\
\alpha=.812\end{array}$ & 1.00 & $\because$ & & & \\
\hline $\begin{array}{l}\text { Contemplation } \\
\alpha=.803\end{array}$ & $-.664 * *$ & 1.00 & & & \\
\hline $\begin{array}{l}\text { Action } \\
\alpha=.756\end{array}$ & $-.366 * *$ & $.687^{* *}$ & 1.00 & & \\
\hline $\begin{array}{l}\text { Maintenance } \\
\alpha=.751\end{array}$ & -.152 & $.365^{* *}$ & $.453^{* *}$ & 1.00 & \\
\hline $\begin{array}{l}\text { Total } \\
\text { Readiness }\end{array}$ & $-.730 * *$ & $.878^{* * *}$ & $.797 * *$ & $.653^{* *}$ & 1.00 \\
\hline
\end{tabular}

** $\mathrm{p}<.001$

Note. Cronbach's Alpha $(\alpha)$ was determined for each subscale. $N$ is the number of items loading into each subscale.

Valid cases out of 74 for each subscale: Pre-Contemplation (72), Contemplation (74), Action (73), Maintenance (73). 


\section{Table 5}

Intercorrelations Between Subscales and Total Social Support on the Source-Specific Social Provisions Scale

\begin{tabular}{|c|c|c|c|c|}
\hline & $\begin{array}{r}\text { Friends } \\
N=12\end{array}$ & $\begin{array}{l}\text { Family } \\
N=12\end{array}$ & $\begin{array}{l}\text { Partner } \\
N=12\end{array}$ & $\begin{array}{c}\text { Total Social Support } \\
\qquad=36 \\
\end{array}$ \\
\hline $\begin{array}{l}\text { Friends } \\
\alpha=.804\end{array}$ & 1.00 & & & \\
\hline $\begin{array}{l}\text { Family } \\
\alpha=.850\end{array}$ & $.244^{*}$ & 1.00 & & \\
\hline $\begin{array}{l}\text { Partner } \\
\alpha=.826\end{array}$ & .236 & $.619^{*}$ & 1.00 & \\
\hline $\begin{array}{l}\text { Total Social } \\
\text { Support } \\
\alpha=.868\end{array}$ & $.365^{* *}$ & $.575^{* *}$ & $.861 * *$ & 1.00 \\
\hline $\begin{array}{l}* p<.05 \\
* * p<.01 \\
\text { Note. Cronbach } \\
\text { loading into eac } \\
\text { Partner (15), an }\end{array}$ & ases out & $\begin{array}{l}\text { :ale and } \\
\text { subscale }\end{array}$ & $\begin{array}{l}\text { ial Supp } \\
\text { Social }\end{array}$ & $\begin{array}{l}\text { is the number of items } \\
\text { t: Friends (69), Family (63) }\end{array}$ \\
\hline
\end{tabular}

A one-way between-groups analysis of covariance was used to compare the degree of social support in each of the five phases using total length of commitment (i.e., time) as the covariate; however, when preliminary checks were conducted to determine if there were violations of the assumptions of normality, linearity, homogeneity of variances, homogeneity of regression slopes, and reliable measurement of the covariate, data indicated the assumptions of linearity and homogeneity of variances were violated. This suggests the covariate and the dependent variable (i.e., social support) were not linear and the variances between the phases are not equal $(\mathrm{F}(4,67)=2.826, p<.05)$. Therefore, the ability to detect differences between phase levels would not improve when 
controlling for total length of commitment. As a result, a one-way between-groups analysis of variance was used. There was not a statistically significant difference at the $p$ $<.05$ level in social support scores between the five phases: $F(4,67)=.212, p=.931$. Post-hoc comparisons using the Tukey HSD test determined mean scores for each of the five phases: phase $1(M=64.25, S D=23.26)$, phase $2(M=64.06, S D=21.86)$, phase 3 $(M=61, S D=11.28)$, phase $4(M=58.70, S D=16.99)$, and phase $5(M=60.50, S D=$ 9.68).

To determine level of motivation to change in each of the five phases, a one-way between-groups analysis of variance was used due to a violation of the assumption of linearity after conducting preliminary checks for the ANCOVA. There was not a statistically significant difference at the $p<.05$ level in motivation to change scores between the five phases: $F(4,69)=1.276, p=.288$. Post-hoc comparisons using the Tukey HSD test determined mean scores for each of the five phases: phase $1(M=9.23$, $S D=2.07)$, phase $2(M=9.28, S D=2.28)$, phase $3(M=10.10, S D=1.98$, phase $4(M=$ $10.51, S D=1.89)$, and phase $5(M=8.50, S D=.49)$.

Hypothesis 2

Offenders with more social support and more motivation to change will engage in less self-defeating behaviors compared to offenders with less social support and less motivation to change using length of commitment as a controlled variable.

Partial correlation was used to explore the relationship between self-defeating behaviors ( $M=30.47, S D=6.09$ ) (as measured by the self-defeating questionnaire) and 
social support (as measured by the Source-Specific Social Provisions Scale) $(M=62.42$, $S D=18.5$ ), while controlling for total length of commitment. There was a significant positive correlation between self-defeating scores and social support, controlling for total length of commitment $\left(r(70)=.235, p=.048, r^{2}=.06\right)$, with fewer self-defeating scores (higher scores indicate fewer self-defeating behaviors) being associated with a higher degree of social support. An inspection of the zero order correlation $(r=.277)$ suggested that controlling for total length of commitment had little effect on the strength of the relationship between these two variables. Social support was not significantly correlated with the total score for the ten treatment areas, the Stable, or the Acute (Table 6).

Table 6

Correlations Between Social Support and Self-Defeating Behaviors

Social Support

\begin{tabular}{|c|c|}
\hline $\begin{array}{l}\text { Self-Defeating } \\
\text { Behaviors }\end{array}$ & $r$ \\
\hline 10 TX Areas 1 & .019 \\
\hline Stable $^{2}$ & -.046 \\
\hline Acute $^{2}$ & -.094 \\
\hline $\begin{array}{l}1 d f=70 \\
* p<.05\end{array}$ & \\
\hline
\end{tabular}

Partial correlation was used to explore the relationship between self-defeating behaviors ( $M=30.47, S D=6.09$ ) (as measured by the self-defeating questionnaire) and motivation to change (as measured by the URICA readiness score) $(M=9.6, S D=2.10)$, while controlling for total length of commitment. There was a significant positive 
correlation between self-defeating scores and motivation, controlling for total length of commitment $\left(r(72)=.287, p=.014, r^{2}=.08\right)$, with fewer self-defeating behaviors (higher scores indicate fewer self-defeating behaviors) being associated with more motivation to change. An inspection of the zero order correlation $(r=.307)$ suggested that controlling for total length of commitment had little effect on the strength of the relationship between these two variables. Motivation to change was not significantly correlated with the total score for the ten treatment areas, the Stable, or the Acute (Table 7).

Table 7

Correlations Between Motivation to Change and Self-Defeating Behaviors Reported by the Therapist

\section{Motivation to Change}

\section{Self-Defeating \\ Behaviors}

$r$

\begin{tabular}{lc}
\hline 10 TX Areas & 154 \\
\hline Stable $^{2}$ & .120 \\
\hline Acute $^{2}$ & .144 \\
\hline${ }^{1} d f=70 \quad{ }^{2} d f=69$ \\
$* p<.05$
\end{tabular}

$\underline{\text { Hypothesis } 3}$

Offenders with less social support and less motivation to change will take longer to progress through treatment over time compared to offenders with more social support and more motivation to change. 
Pearson product-moment correlation coefficient was used to determine social support and motivation in relation to progression through treatment over time. No significant correlation $(r(72)=-.075, p=.530)$ was found between total social support $(M=62.42, S D=18.5)$ and progression through treatment $(M=28.53, S D=20.46)$, or between motivation to change $(M=9.6, S D=2.10)$ and progress through treatment $(M=$ 28.53, $S D=20.46)(r(74)=-.209, p=.074)$.

Additional analyses were used to determine if there was a relationship between self-defeating behaviors and progress through treatment using Pearson product-moment correlation coefficients (Table 8).

Table 8

Correlations Between Self-Defeating Measures and Average Time in a Phase

\begin{tabular}{lllcc}
\hline & Stable & Acute & 10 TX Areas & $\begin{array}{c}\text { Self-Defeating } \\
\text { Questionnaire }\end{array}$ \\
\hline $\begin{array}{c}\text { Average Time } \\
(\boldsymbol{r})\end{array}$ & $-.357^{* * *}$ & $-.323^{* *}$ & -.132 & $-.355^{* *}$ \\
\hline$* * \boldsymbol{p}<. \mathbf{0 1}$ & & & & \\
\hline
\end{tabular}

This table shows the correlations between self-defeating behavior scores and the average time in a phase. There were significant negative correlations between the Stable $(M=$ $5.2, S D=2.82)$, Acute $(M=9.09, S D=3.91)$, the self-defeating questionnaire $(M=$ $30.47, S D=6.09)$ and average time in a phase $(M=28.52, S D=20.48)$ indicating the more time in a phase, the more self-defeating behaviors that occurred. There was not a 
significant relationship between scores in the ten treatment areas and average time in a phase.

Hypothesis 4

Offenders who have been in treatment longer will endorse higher scores in the maintenance stage compared to the pre-contemplation, contemplation, and action stage.

The relationship between total length of commitment and maintenance stage (as measured by the total score in the maintenance stage using the URICA) was investigated using Pearson product-moment correlation coefficient. There was not a significant relationship between maintenance stage $(M=26.65, S D=5.71)$ and length of commitment $(M=72.79, S D=16.15)(r(74)=.089, p=.449)$.

Additional Pearson product-moment correlation coefficients were used to investigate total length of commitment and scores on the three additional stages (Table 9). Results suggest that offenders who endorsed higher scores in the contemplation stage of change have been in treatment for fewer months. 
Table 9

Correlations Between Motivation Subscales and Total Length of Commitment

\begin{tabular}{|c|c|c|c|c|}
\hline & $\begin{array}{c}\text { Pre- } \\
\text { Contemplation } \\
N=74 \\
M=15.73 \\
S D=\mathbf{5 . 9 3}\end{array}$ & $\begin{array}{c}\text { Contemplation } \\
N=74 \\
M=32.85 \\
S D=4.9\end{array}$ & $\begin{array}{c}\text { Action } \\
N=74 \\
M=32.57 \\
S D=4.74\end{array}$ & $\begin{array}{c}\text { Maintenance } \\
N=74 \\
M=26.65 \\
S D=5.71\end{array}$ \\
\hline $\begin{array}{c}\text { Total length of } \\
\text { commitment } \\
(M=72.8, \\
S D=41.2)\end{array}$ & .204 & $-.239^{*}$ & -.089 & .089 \\
\hline
\end{tabular}

Hypothesis 5

Offenders with fewer phase penalties will have more social support and more motivation to change.

Partial correlation was used to explore the relationship between social support ( $M$ $=62.42, S D=18.5)$ and phase penalties $(M=.51, S D=.85)$, while controlling for total length of commitment. There was not a significant correlation between social support and phase penalties, controlling for total length of commitment $(r(65)=.138, p=.285)$.

Partial correlation was used to explore the relationship between motivation $(M=$ 9.6, $S D=2.10)$ and phase penalties $(M=.51, S D=.85)$, while controlling for total length of commitment. There was not a significant correlation between motivation and phase penalties, controlling for total length of commitment $(r(65)=-.106, p=.405)$. 


\section{Supplemental Analyses}

The internal reliability of the self-defeating questionnaire was $\alpha=.57$. Inter-item correlations determined that the question regarding "anxiety to be released" had the weakest correlation with the total score $(r=.193)$. Pearson product-moment correlation coefficients were used to determine if there were relationships between total perceived social support and the individual sources of social support and total readiness to change and the motivation subscales. Results did not yield significant correlations between the scales.

A Pearson product-moment correlation coefficient was used to determine the relationship between length of commitment, perceived sources of social support and total social support; time was not used as a covariate. There was a significant negative relationship between perceived social support received from a partner $(M=30.60, S D=$ $5.12)$ and length of commitment $(M=72.80, S D=41.20 ;(r(13)=-.542, p=.037)$; however there was not a significant relationship between perceived social support received from family $(M=27.57, S D=6.36 ;(r(65)=-.223, p=.07)$, and friends $(M=$ $30.39, S D=4.91 ;(r(70)=-.135, p=.258)$ and length of commitment. Results did not yield a significant relationship between total perceived social support $(M=62.42, S D=$ 18.50) length of commitment $(r(70)=-.195, p=.101)$.

Pearson product-moment correlation coefficients were used to determine the relationship between self-reported defeating behaviors and behaviors reported by the therapists (Table 10). 
Table 10

Correlations Between Self-Defeating Questionnaire and Defeating Behaviors Reported by the Therapists

\begin{tabular}{lc}
\hline & $\begin{array}{c}\text { Self-Defeating } \\
\text { Questionnaire } \\
r\end{array}$ \\
\hline Stable & .203 \\
Acute & .145 \\
10 TX & .101 \\
Areas & \\
\hline
\end{tabular}

A breakdown of partial correlations between self-defeating behaviors, motivation to change and subscales, and sources of social support are noted in Table 11 and Table 12.

Table 11

Correlations Between Self-Defeating Behaviors and Social Support

\begin{tabular}{lccccc}
\hline $\begin{array}{l}\text { Self-Defeating } \\
\text { Behaviors }\end{array}$ & $\begin{array}{c}\text { Social } \\
\text { Support } \\
\text { Total }\end{array}$ & Friends & Family & Partner & $\begin{array}{c}\text { Friends and } \\
\text { Family }\end{array}$ \\
\hline $\begin{array}{l}\text { Self-Defeating } \\
\text { Questionnaire }\end{array}$ & $.24^{*}$ & $.45^{* *}$ & .07 & .42 & $.32^{* *}$ \\
$\begin{array}{l}\text { 10 Treatment } \\
\text { Areas } \\
\text { Stable }\end{array}$ & .02 & $.25^{*}$ & .12 & .12 & .21 \\
Acute & -.05 & $.29 *$ & -.07 & .00 & .12 \\
\hline $\begin{array}{l}* p<.05 \\
* * p<.01\end{array}$ & -.09 & .13 & -.18 & -.38 & .04 \\
& & & & & \\
\end{tabular}


Table 12

Correlations Between Self-Defeating Behaviors and Motivation to Change

\begin{tabular}{lccccc}
\hline $\begin{array}{l}\text { Self- } \\
\text { Defeating } \\
\text { Behaviors }\end{array}$ & $\begin{array}{c}\text { Total } \\
\text { Readiness }\end{array}$ & $\begin{array}{c}\text { Pre- } \\
\text { Contemplation }\end{array}$ & Contemplation & Action & Maintenance \\
\hline $\begin{array}{l}\text { Self- } \\
\text { Defeating }\end{array}$ & $.29^{*}$ & $-.37^{* *}$ & $.48^{* *}$ & .42 & -.22 \\
$\begin{array}{l}\text { Questionnaire } \\
\text { 10 Treatment }\end{array}$ & .15 & -.21 & .12 & .12 & -.08 \\
$\begin{array}{l}\text { Areas } \\
\text { Stable }\end{array}$ & .12 & -.21 & & & \\
& & & .05 & .00 & -.00 \\
Acute & .14 & -.20 & .09 & -.38 & .05 \\
\hline${ }^{*} p<.05$ & & & & & \\
$* * 01$ & & & & & \\
\end{tabular}

Linear regressions were used to determine if certain factors predicted selfdefeating behaviors. Factors such as being on probation or parole previously, and level of education did not predict perceived self-defeating behaviors. Regression analyses were also used to determine if social support and motivation to change predicted average amount of time in a phase. Results suggest motivation to change and social support do not predict how long an offender is in a phase of treatment.

Partial correlations were used to determine if social support and motivation to change were related to each of the 10 treatment areas (Table 13 and Table 14). 
Table 13

Partial Correlations Between Social Support and 10 Treatment Areas

\begin{tabular}{|c|c|c|c|c|c|}
\hline Treatment Area & Friends & Family & Partner & $\begin{array}{l}\text { Friends and } \\
\text { Family }\end{array}$ & $\begin{array}{c}\text { Total Socia } \\
\text { Support }\end{array}$ \\
\hline
\end{tabular}

\begin{tabular}{|c|c|c|c|c|c|}
\hline Disclosure & .218 & .214 & .047 & $.280 *$ & .092 \\
\hline Insight & $.311^{* *}$ & .155 & .017 & $.267^{*}$ & .110 \\
\hline $\begin{array}{l}\text { Personal } \\
\text { Victimization }\end{array}$ & .220 & .117 & -.135 & .221 & .023 \\
\hline Empathy & $.264 *$ & .130 & -.054 & .221 & .071 \\
\hline $\begin{array}{l}\text { Health, } \\
\text { Hygiene, and } \\
\text { Leisure }\end{array}$ & .132 & .033 & .171 & .076 & -.075 \\
\hline $\begin{array}{l}\text { Cognitive } \\
\text { Coping Skills }\end{array}$ & .173 & .078 & -.224 & .083 & -.086 \\
\hline $\begin{array}{l}\text { Sexual } \\
\text { Behaviors }\end{array}$ & $.350 * *$ & .125 & .361 & $.272 *$ & .111 \\
\hline $\begin{array}{l}\text { Relapse } \\
\text { Prevention }\end{array}$ & $.312 * *$ & .151 & .343 & $.253^{*}$ & .004 \\
\hline Intimacy Skills & .132 & -.007 & -315 & .142 & .024 \\
\hline $\begin{array}{l}\text { Problem } \\
\text { Solving Skills }\end{array}$ & .167 & .021 & -.243 & .082 & -.093 \\
\hline
\end{tabular}


Table 14

Partial Correlations Between Motivation to Change and 10 Treatment Areas

\begin{tabular}{|c|c|c|c|c|c|}
\hline $\begin{array}{c}\text { Treatment } \\
\text { Area }\end{array}$ & $\begin{array}{c}\text { Pre- } \\
\text { Contemplation }\end{array}$ & $\begin{array}{l}\text { Contemp- } \\
\text { lation }\end{array}$ & Action & Maintenance & $\begin{array}{c}\text { Total } \\
\text { Readiness } \\
\end{array}$ \\
\hline Disclosure & -.247 & .137 & .141 & .003 & .176 \\
\hline Insight & -.151 & .086 & .153 & -.057 & .113 \\
\hline $\begin{array}{l}\text { Personal } \\
\text { Victimizati } \\
\text { on }\end{array}$ & -.212 & .151 & .211 & -.082 & .162 \\
\hline Empathy & -.168 & .120 & .257 & -.031 & .166 \\
\hline $\begin{array}{l}\text { Health, } \\
\text { Hygiene, } \\
\text { and } \\
\text { Leisure }\end{array}$ & $-.332 * *$ & .223 & $.263^{*}$ & -.083 & $.244^{*}$ \\
\hline $\begin{array}{l}\text { Cognitive } \\
\text { Coping } \\
\text { Skills }\end{array}$ & -.160 & .094 & .199 & -.032 & .141 \\
\hline $\begin{array}{l}\text { Sexual } \\
\text { Behaviors }\end{array}$ & -.066 & .035 & .148 & -.156 & .027 \\
\hline $\begin{array}{l}\text { Relapse } \\
\text { Prevention }\end{array}$ & -.211 & . 117 & .228 & -.084 & 149 \\
\hline $\begin{array}{l}\text { Intimacy } \\
\text { Skills }\end{array}$ & -.161 & .049 & .185 & -.111 & .098 \\
\hline $\begin{array}{l}\text { Problem } \\
\text { Solving } \\
\text { Skills } \\
\end{array}$ & -.209 & . 115 & $.240^{*}$ & -.036 & 179 \\
\hline
\end{tabular}




\section{CHAPTER 4}

\section{DISCUSSION}

When lower levels of perceived social support are combined with lower degrees of motivation an offender has to change his behavior, it was hypothesized that an offender would be in a lower phase level of treatment; therefore, making less progress compared to offenders with more social support and higher levels of motivation. However, results suggested that offenders who are in lower phase levels do not have less social support and lower levels of motivation compared to offenders in higher phase levels (e.g., those who are making better progress through treatment). It was thought that because some offenders have been in treatment longer (e.g., years) and have had the opportunity to progress through the phases of treatment more so than offenders who have only been in treatment for a few months, that length of commitment should be held constant. However, results indicated that the length of commitment does not impact the phase an offender is in regardless of their perceived social support and level of motivation.

Social support and total readiness to change impact the number of self-defeating behaviors reported by offenders. This suggests that the more total perceived social support and motivation to change offenders have, the fewer self-defeating behaviors they perceive themselves as having. This does not suggest that the offenders are actually engaging in fewer self-defeating behaviors. In fact, the amount of total perceived social support and total readiness to change do not have an impact on self-defeating behaviors when those behaviors are reported by therapists, as opposed to the offenders' self-report. Further, when relying on therapists' ratings, offenders who have more social support from 
friends compared to family and their partner, they engage in fewer self-defeating behaviors.

Less social support and less motivation to change was hypothesized to prolong progress through treatment (i.e., the average amount of time offenders have been in a phase). However, social support and level of motivation to change did not prolong the average length of time to complete a phase. Supplemental analyses indicated that offenders who engage in more self-defeating behaviors spend more time in a phase. Similarly, offenders who are reported by their therapist to engage in more self-defeating behaviors spend more time in a phase. The more offenders engage in problematic behaviors, the worse they are doing in treatment, which increases the average amount of time they spend in a phase.

It was hypothesized that offenders who have been in treatment longer would endorse their highest scores in the maintenance stage of treatment suggesting they have "fixed" their problem and are working to continue changing. However, offenders endorsed their highest scores on the contemplation subscale. This suggests they are still uncertain if they have problems that require changing. Many conclusions can be drawn from this finding. Offenders who do not think they have a problem would score high on the contemplation subscale. Similarly, offenders who believe they have been in treatment long enough and have "fixed" their problem would also score high on this subscale.

Offenders, at times, violate the guidelines of treatment which consequently result in loss of a phase. These phase penalties were not indicative of the level of social support and motivation to change suggesting that even if an offender had more social support and 
high levels of motivation, it did not mean he was penalized by being placed in a lower phase level.

Supplemental analyses suggest that offenders who are less ready to change engage in fewer self-defeating behaviors (as rated by the offender). This is counterintuitive in that it was hypothesized offenders who were more ready to change would engage in fewer self-defeating behaviors. When self-defeating behaviors were rated by therapists, however, the degree of motivation did not impact the number of self-defeating behaviors. This suggests a discrepancy between offenders' and therapists' ratings of self-defeating behaviors. The offenders think they are engaging in fewer self-defeating behaviors when they have high levels of motivation when in reality the level of motivation does not impact the number of self-defeating behaviors according to the therapists.

Offenders who perceived themselves as having more social support from friends and family disclose more about their offenses in treatment and have more insight into the various social, behavioral, emotional, and cognitive factors that contributed to their offending behavior. Offenders who perceived themselves as having more social support from friends show greater degrees of empathy, remorse, and an understanding of the impact of their sexual offending. Similarly, offenders with more perceived social support from friends show a greater degree of altering dysfunctional sexual behaviors and recognizing deviant sexual arousal. This leads to the offenders having a greater ability to develop a comprehensive relapse prevention plan. The relapse prevention plan is meant to identify general contextual interventions that reduce the likelihood of offending. 
In terms of motivation, offenders who are not sure whether or not they have a problem have lower quality health, hygiene, and fewer leisure skills (e.g., personal goals). This suggests they have greater difficulty practicing health and hygiene and have developed fewer personally meaningful goals. On the other hand, offenders with more motivation to change have been able to demonstrate more acceptable health and hygiene practices and have developed meaningful personal goals (e.g., goals planned for potential release into the community). Offenders who are taking action and have identified that that have a problem have better problem solving skills. This suggests that they are better at communicating and are better able to address emotional regulation and cognitive distortions that result in ineffective skills.

\section{Limitations}

The a priori power analysis conducted prior to data collection determined that 82 participants was sufficient to detect an effect and is consistent with Cohen's (1988) recommendations that a total of 85 participants would be sufficient to detect an effect. The sample size of the current study may have affected the ability to detect differences as its sample size was 74 .

Another factor to consider is that the URICA used in the study to determine level of motivation to change is typically used prior to treatment. However, for purposes of this sample it was not possible to administer the measure prior to treatment. In this case, offenders who have been in treatment for years may think they have "fixed" their problem and do not need to change. As a result, they may score higher on the pre- 
contemplation and contemplation stages of change because they feel their problems have been handled.

Additional limitations in the study include the lack of internal consistency between the pre-contemplation and maintenance subscales. This may be due to restriction of range in the pre-contemplation stage of change. A previous study using the URICA in a sample of sexual offenders noted a mean score of 30.6 in the precontemplation stage of change with a correlation between the pre-contemplation and motivation subscales of -.64 (Tierney \& McCabe, 2004). In the current study the mean score in the pre-contemplation subscale was only 15.73 and did not significantly correlate with the maintenance subscale. However, it did yield a negative correlation as was found in the Tierney and McCabe (2004) study. As with most studies, a small sample size may limit the power needed to detect an effect.

Several "limitations" are a result of collecting in a dynamic, real-world environment. For example, there were not an equal number of offenders in each of the five phases. Specifically, there were six times the number of offenders in phase 2 compared to phase 5, which may have affected the ability to detect differences when comparing offenders in different phases. Further, not all offenders had complete 90-day evaluation records. This impacted the ability to calculate average length of time to complete a phase. Only two percent of the most recent 90-day evaluations were missing; however out of the 1,291 90-day evaluations collected, some evaluations were not able to be located in the archives. This, in part, was due to CCUSO's transition from hard copy files to computer files. Due to the complexity of the collection of 90-day evaluations it 
was not possible to keep track of the number of total missing evaluations. And finally, the low number of phase penalties in this sample of sexual offenders made it difficult to detect the impact of social support and level of motivation to change; the average number of phase penalties was less than one. One of CCUSO's strategies to motivate offenders is to continuously increase their scores in the 10 treatment areas even if by $1 / 4^{\text {th }}$ of a point. For example, if an offender has a score of 4 in one of the ten treatment areas, but has not made progress in that area come evaluation time, some therapists in the facility will bump the offender's score up slightly to create a sense of progress made in that area of treatment. As a result, a goal of some therapists is to increase treatment area scores even if progress has not been made; therefore, the likelihood an offender will have a phase penalty is small.

Implications

Social support and motivation to change may serve as protective factors at the individual level. If offenders feel as though they have more social support and are more motivated to change, they are less likely to engage in self-defeating behaviors. The mere thought of having more social support is beneficial for offenders especially in treatment settings that are long-term where offenders may lose touch with their social support groups. Furthermore, having more perceived social support, particularly from friends and family, helps offenders do better in certain areas of treatment (e.g., disclosing offenses and having insight into the factors that lead to their offenses). Offenders, however, do not benefit in other areas of treatment (e.g., cognitive coping skills and problem solving skills) even if they have more social support. This finding may suggest that the mere 
perception of having social support does not help offenders with their ability to solve and cope with their problems.

When determining levels of motivation to change in this sample of offenders, the majority of offenders were in the contemplation stage of change and their readiness to change score (9.6) suggested that the offenders still did not know if they had a problem they wanted to fix. DiClemente, Schlundt and Gemmell (2004) note that scores below 8 are indicative of being in the pre-contemplation stage of change, scores between 8 and 11 are indicative of being in the contemplation stage of change. In clinical and treatment settings, determining the stages of change is important for targeting problematic areas and effectively treating them. This may be problematic in group treatment settings where there is greater likelihood that offenders will be in different stages of change. Motivation, however, is still a critical part of treatment and because the majority of offenders are still in the contemplation stage of change (e.g., do not know if they have a problem worth changing), then this is likely impacting their ability to progress through treatment.

\section{Future Research}

Future research should examine other factors that may play a role in self-defeating behaviors. Positive outcomes are not likely within these populations and self-defeating behaviors may not be the only inhibiting factor of slow progress through treatment. As discussed previously, civilly committed sexual offenders have to go through a process upon release of their prison sentence if they "appear" to meet the criteria for civil commitment by the jurisdiction in which they reside. This process of civil commitment 
deems that the most dangerous sexual offenders have a mental abnormality that prevents them from having the cognitive ability to resist reoffending. Research should focus on the mental abnormality the offenders are deemed likely to possess. If treatment progress is problematic, the mental abnormality may play a role and hinder treatment progress. Therefore, the offenders may be set up to fail because the treatment program is not designed for individuals with such an abnormality.

Research should also focus on the stage of change the offenders are in upon entering treatment. Centers housing civilly committed offenders may find that some offenders come in with varying levels of motivation and other skill sets. Individual therapy is not plausible in these facilities; therefore, therapists conduct treatment in groups. If individuals in each of these groups are in different stages of change, there are implications. For example, an offender in treatment in the pre-contemplation stage would require a treatment approach for exploring the problematic behavior, whereas an offender in treatment in the action phase has already identified the problematic behavior and is more ready to change. Group therapy should target all aspects of the stages of motivation in which the offenders find themselves in, which may lead to greater levels of motivation.

IQ may also play a role in the lack of progress through treatment. The average reading level at CCUSO is $6^{\text {th }}$ grade according to the CCUSO's clinical director. If offenders do not have IQ's in the average range of intellectual development, it may limit their ability to progress through treatment. The average reading level ( $6^{\text {th }}$ grade) is not consistent with actual education levels in this study: $45 \%$ of offenders have completed high school. Therefore, future research should focus on offender IQ in civil commitment 
units and the implications that may result. Future research should determine the average IQ for this population of offenders and compare the IQ scores to IQ scores of offenders who are not committed. If research finds overall lower IQ scores this is problematic as the criteria to be civilly committed may need to be revised. Also, if IQ is found to be lower, it may have implications for the treatment of their mental abnormality.

\section{Conclusion}

Offenders who have more social support and more motivation to change may perceive themselves to engage in fewer self-defeating behaviors. However, when therapists evaluate offenders' self-defeating behaviors to determine progress in treatment, the more social support and more motivation to change do not decrease self-defeating behaviors. As a result, level of social support and motivation to change may act as a protective factor at the individual level. Treatment should focus on offenders recognizing when their behaviors are affecting their treatment and treatment should be tailored to the appropriate stage of change. For example, if offenders do not think they have a problem and the treatment being used targets individuals who have identified a problem, then the treatment will not be effective and should be restructured.

The discrepancy between therapist and offender perception of self-defeating behaviors indicates that offenders may not understand their self-defeating behaviors as accurately as their therapists understand them. Similarly, offenders may not view certain behaviors as self-defeating, when in fact they are. If therapists and offenders are on the same page and have an understanding of what constitutes self-defeating behaviors, then 
offenders may become more aware of what behaviors are more helpful versus harmful (e.g., inhibit progress in treatment).

More perceived social support from friends compared to other sources of social support (e.g., family and partner) was related to having greater degrees of empathy, remorse, and an understanding of the impact of sexual offending (as rated by therapists). Perceived social support from friends and family, in turn, was related to disclosing previous crimes and having more insight into factors that contributed to their offenses (again, as rated by therapists). Overall, higher degrees of perceived social support from friends was related to doing better in the treatment areas of insight, empathy, sexual behaviors, and relapse prevention. In terms of motivation, offenders who were more ready to change did better maintaining their health and hygiene, and have developed meaningful personal goals (e.g., goals planned for potential release into the community). These specific areas of treatment (e.g., insight, empathy, etc.) are critical for the offender to maintain and do well in if the ultimate goal is eventual release. Social support systems in civil commitment units should be encouraged as it has been found to play a role in critical areas of treatment. Having higher degrees of motivation to change have been found to increase health and hygiene behaviors. Similarly, offenders who are more motivated are more likely to make positive future goals compared to offenders who are not motivated. Although higher degrees of motivation to change and more social support do not result in fewer self-defeating behaviors overall (as rated by therapists), it does play a role in important areas of treatment. 


\section{REFERENCES}

Barrett, M., Wilson, R.J., \& Long, C. (2003). Measuring motivation to change in sexual offenders from institutional intake to community treatment. Sexual Abuse: $A$ Journal of Research and Treatment, 15(4), 269-283.

Baumeister, R.F., Brewer, L.E., Tice, D.M., \& Twenge, J.M. (2007). Thwarting the need to belong: Understanding the interpersonal and inner effects of social exclusion. Social and Personality Psychology, 1, 506-520.

Baumeister, R. F., \& Scher, S. J. (1988). Self-defeating behavior patterns among normal individuals: review and analysis of common self-destructive tendencies. Psychological Bulletin, 104,(1), 3-22.

Bonnar-Kidd, K.K. (2010). Sexual offender laws and prevention of sexual violence or recidivism. American Journal of Public Health, 100(3), 412-419.

Bureau of Justice Statistics. (2003). Recidivism of sex offenders released from prison in 1994 (No. NCJ 198281). Washington, DC: U.S. Department of Justice.

Burns, M. (2009, January 28). SOL research: Civil Commitment of Sex Offenders. Retrieved from solresearch.org

Cohen, J. (1988). Statistical power analysis for the behavioral sciences $\left(2^{\text {nd }}\right.$ ed). New Jersey: Lawrence Erlbaum Associates, Inc.

Crowne, D.P., \& Marlowe, D. (1960). A new scale of social desirability independent of psychopathology. Journal of Consulting Psychology, 24, 349-354.

Curtis, R. C. (1989). Self-defeating behaviors: Experimental research, clinical impressions, and practical implications. New York: Plenum Press.

Cutrona, C.E. (1989). Ratings of social support by adolescents and adult informants: Degree of correspondence and prediction of depressive symptoms. Journal of Personality and Social Psychology, 57(4), 723-730.

Cutrona, C.E., \& Russell, D.W. (1987). The provisions of social relationships and adaptation to stress. Advances in Personal Relationships, 1, 37-67.

DiClemente, C.C., Bellino, L.E., \& Neavins, T.M. (1999). Motivation for change and alcoholism treatment. Alcohol Research \& Health, 23(2), 86-92. 
DiClemente, C. C., \& Hughes, S. O. (1990). Stages of change profiles in outpatient alcoholism treatment. Journal of Substance Abuse, 2(2), 217-235.

DiClemente, C., Schlundt, D., \& Gemmell, L. (2004). Readiness and stages of change in addiction treatment. The American Journal on Addictions, 13:103-119.

Duwe, G., \& Donnay, W. (2008). The impact of Megan's Law on sex offender recidivism: The Minnesota experience. Criminology, 46(2), 411-446.

Faul, F., Erdfelder, E., Lang, A.-G., \& Buchner, A. (2007). G*Power 3: A flexible statistical power analysis for the social, behavioral, and biomedical sciences. Behavior Research Methods, 39, 175-191

Florida Department of Law Enforcement. (2007). Guidelines to Florida sex offender laws. Retrieved February 20, 2012, from http://offender.fdle.state.fl.us/offender/LegalBulletin.jsp\#Intro

Gookin, K. (2007). Comparison of state laws authorizing involuntary commitment of sexually violent predators: 2006 update revised. Retrieved April 15, 2011, from http://www.wsipp.wa.gov/pub.asp?docid=07-08-1101

Gutierrez-Lobos, K., Eher, R., Grunhun, C., Bankier, B., Schmidl-Mohl, B., Fruhwald, S., \& Semler, B. (2001). Violent sex offenders lack male social support. International Journal of Offender Therapy and Comparative Criminology, 45(1), 70-82.

Hanson, R. K., Harris, A. J. R., Scott, T. L., \& Helmus, L. (2007). Assessing the risk of sexual offenders on community supervision: The Dynamic Supervision Project (User Report 2007-05). Ottawa, ON: Public Safety Canada.

Heil, P., \& English, K. (2007). Prison sex offender treatment: Recommendations for program implementation. Report for California Department of Corrections and Rehabilitation. Retrieved February 21, 2012, from http://www.casomb.org/docs/PSOT_CDCR_Report.pdf

Jacoby, J.E., \& Kozie-Peak, B. (1997). The benefits of social support for mentally ill offenders: Prison-to-community transitions. Behavioral Sciences and the Law, 15, 483-501.

Langan, P.A., Schmitt, E.L., \& Durose, M.R. (2003). Recidivism of sex offenders released from prison in 1994. Bureau of Justice Statistics. Retrieved February 2, 2011, from http://bjs.ojp.usdoj.gov/index.cfm?ty=pbdetail\&iid=1136 
Levenson, J.S., \& Cotter, L.P. (2005). The effect of Megan's law on sex offender reintegration. Journal of Contemporary Criminal Justice, 21, 49-66. doi: $10.1177 / 1043986204271676$

Levenson, J.S., D'Amora, D.A., \& Hern, A.L. (2007). Megan's law and its impact on community re-entry for sex offenders. Behavioral Sciences and the Law, 25, 587602. doi: $10.1002 / \mathrm{bsl} .770$

Lin, N., Dean, A., \& Ensel, W.M. (1986). Social support, life events, and depression. New York: Academic Press.

McConnaughy, E.A., Prochaska, J.O., \& Velicer, W.F. (1983). Stages of change in psychotherapy: Measurement and sample profiles. Psychotherapy, Theory, Research, and Practice, 20(3), 368-375.

McMurran, M. (Ed.). (2002). Motivating offenders to change. New York: John Wiley \& Sons, Inc.

Meyer-III, W.J., Molett, M., Richards, C.D., Arnold, L., \& Latham, J. (2003). Outpatient civil commitment in Texas for management and treatment of sexually violent predators: A preliminary report. International Journal of Offender Therapy and Comparative Criminology, 47(4), 396-406. doi: 10.1177/0306624X03253846

Miller, J. (2010). Sexual offender civil commitment: The treatment paradox. California Law Review, 98, 2093-2128.

National Alert Registry. (n.d.). Retrieved November 10, 2010 from http://www.sexoffenderfinder.com/statistics.htm

The National Center for Victims of Crime (2008). Child Sexual Abuse. Retrieved on November 23, 2011, from http://www.ncvc.org/ncvc/Main.aspx

Sandler, J. C., Freeman, N.J., \& Socia, K.M. (2008). "Does a Watched Pot Boil: A TimeSeries Analysis of New York State's Sex Offender Registration and Notification Law." Psychology, Public Policy, and Law, 14(4), p. 284-302.

Sarason, I.G., Levine, H.M., Basham, R.B., \& Sarason, B.R. (1983). Assessing social support: The social support questionnaire. Journal of Personality and Social Psychology, 44(1), 127-139.

Sarason, B.R., Pierce, G.R., Shearin, E.N., Sarason, I.G., \& Waltz, J.A. (1991). Perceived social support and working models of self and actual others. Journal of Personality and Social Psychology, 60, 273-287. 
Sarason, I.G., Sarason, B.R., Shearin, E.N., \& Pierce, G.R. (1987). A brief measure of social support: Practical and theoretical implications. Journal of Social and Personal Relationships, 4, 498-510.

Sexually Violent Predator Act. Iowa Code $\S$ Chapter 229A Commitment of Sexually Violent Predators (1998).

Snyder, H.N. (2000). Sexual assault of young children as reported to law enforcement: Victim, incident, and offender characteristics. Bureau of Justice Statistics. Retrieved February 15, 2011, from http://bjs.ojp.usdoj.gov/index.cfm?ty=pbdetail\&iid $=1147$

Terry, K.J., \& Mitchell, E.W. (2001). Motivation and sex offender treatment efficacy: Leading a horse to water and making it drink? International Journal of Offender Therapy and Comparative Criminology, 45(6), 663-672. doi: $10.1177 / 0306624 \times 01456003$

Thau, S., Aquino, K., \& Poortvliet, P.M. (2007). Self-defeating behaviors in organizations: The relationship between thwarted belonging and interpersonal work behaviors. Journal of Applied Psychology, 92(3), 840-847. doi: 10.1037/0021-9010.32.3.840

Tice, D.M., \& Baumeister, R.F. (1997). Longitudinal study of procrastination, performance, stress, and health: The costs and benefits of dawdling. Psychological Science, 8(6), 454-458.

Tierney, D.W., \& McCabe, M.P. (2004). The assessment of motivation for behaviour change among sex offenders against children: An investigation of the utility of the stages of change questionnaire. Journal of Sexual Aggression, 10(2), 237-249. doi: $10.1080 / 13552600412331289014$

Titus, S. (n.d.). Iowa Department of Human Services. Retrieved February 15, 2011, from http://www.dhs.state.ia.us/docs/2012-Offer-401-HHS-014-Civil-CommitmentUnit-for-Sexual-Offenders-Narrative.pdf

Twenge, J. M., Catanese, K. R., \& Baumeister, R. F. (2002). Social exclusion causes selfdefeating behavior. Journal of Personality and Social Psychology, 83, 606-615.

Williams, K.M., Cooper, B.S., Howell, T.M., Yuille, J.C., \& Paulhus, D.L. (2009). Inferring sexually deviant behavior from corresponding fantasies: The role of personality and pornography. Criminal Justice and Behavior: An International Journal, 36(2), 198-222). 
Witt, P.H. \& Schneider, J. (2005). Managing sex offenders by assessing dynamic risk factors. Sex Offender Law Report, 6, pp.49, 54-57.

Zonana, H. (1997). The civil commitment of sex offenders. American Association for the Advancement of Science, 278, 1248-1249. 
APPENDIX A

DEMOGRAPHICS

\section{Characteristics About Yourself}

What is your age?

Please indicate the race/ethnicity that you most closely identify with (Please check one).

Asian

African American

Hispanic/Latino

Caucasian/White

Native American Indian

Multiracial

Would rather not say

Other (Please specify)

Please indicate your marital status.

Single

In a committed relationship

Married

Divorced

Widowed

Separated

Would rather not say

How many children do you have?

What is the highest level of education you have completed?

Grammar school/Elementary School

High school or equivalent

Vocational school/ technical school (2 year)

Some college

Bachelor's Degree

Master's Degree

Doctoral Degree

Licensure/Certification (please specify) 
Have you been in a sexual offender treatment program other than CCUSO?

No

Yes (If yes, please specify the type and how many times).

For example: Inpatient

Inpatient

Outpatient

While in prison

Other

Have you ever been on probation?

No

apply)

Yes (If yes, did you ever violate any terms of the probation? Please check all that

Curfew

Substance use

Being out of place of assignment (e.g., went beyond restricted limits)

Other

I have never violated my probation

Have you ever been on parole?

No apply)

Yes (If yes, did you ever violate any terms of the parole? Please check all that

Curfew

Substance use

Being out of place of assignment (e.g., went beyond restricted limits) Other

I have never violated my parole 


\section{Characteristics About Your Victims}

What age group(s) of people have you offended against? (Please check all that apply).

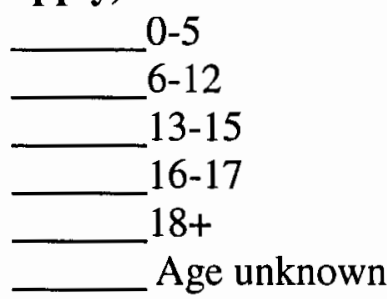

What was the gender of your victim(s)?

Female

Male

Both male and female

Did you know your victim(s)?

\begin{tabular}{l} 
No \\
\hline Yes \\
\hline
\end{tabular}

What was your relationship with your victim(s)? (Please check all that apply). Stranger

Acquaintance

Friend

Family member 


\section{APPENDIX B \\ SOURCE-SPECIFIC SOCIAL PROVISIONS SCALE}

In answering the next set of questions, please think about your current relationships with your friends. If you feel a question accurately describes your relationships with your friends you would say "yes". If the question does not describe your relationships, you would say "no". If you cannot decide whether the question describes your relationships with your friends you may say "not sure". If you do not have any friends, please continue to the next page.

1) $\mathrm{NO}$

2) SOMETIMES

3) YES

1. Are there friends you can depend on to help you if you really need it?

2. Do you feel you could not turn to your friends for guidance in times of stress? $\mathrm{R}$

3. Are there friends who enjoy the same social activities that you do?

4. Do you feel personally responsible for the well-being of your friends?

5. Do you feel your friends do not respect your skills and abilities? $\mathrm{R}$

6. If something went wrong, do you feel that none of your friends would come to your assistance? R

7. Do your relationships with your friends provide you with a sense of emotional security and well-being?

8. Do you feel your competence and skill are recognized by your friends?

9. Do you feel none of your friends share your interests and concerns?

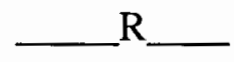

10. Do you feel none of your friends really rely on you for their well-being? 
11. Is there a trustworthy friend you could turn to for advice if you were having problems? R

12. Do you feel you lack emotional closeness with your friends? 
In answering the next set of questions, please think about your current relationships with your familv. This can include your parents, siblings, children, or other family members, but it does not include your romantic partner. If you do not have any family, please continue to the next page.

1) NO

2) SOMETIMES

3) YES

1. Can you depend on your family to help you if you really need it?

2. Do you feel you could not turn to your family for guidance in times of stress? R

3. Does your family enjoy the same social activities that you do?

4. Do you feel personally responsible for the well-being of your family?

5. Do you feel your family does not respect your skills and abilities? R

6. If something went wrong, do you feel that your family would not come to your assistance? $\mathrm{R}$

7. Does your relationship with your family provide you with a sense of emotional security and well-being?

8. Do you feel your competence and skill are recognized by your family?

9. Do you feel your family does not share your interests and concerns? R

10. Do you feel your family does not really rely on your for their well-being? $\mathrm{R}$

11. Could you turn to your family for advice if you were having problems?

12. Do you feel you lack emotional closeness with your family? 
In answering the next set of questions, please think about your current relationships with your romantic partner. If you do not have a romantic partner, please continue to the next page.
1) $\mathrm{NO}$
2) SOMETIMES
3) YES

1. Can you depend on your partner to help you if you really need it?

2. Do you feel you could not turn to your partner for guidance in times of stress?

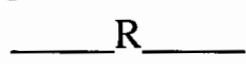

3. Does your partner enjoy the same social activities that you do?

4. Do you feel personally responsible for the well-being of your partner?

5. Do you feel your partner does not respect your skills and abilities? R

6. If something went wrong, do you feel that your partner would not come to your assistance? R

7. Does your relationship with your partner provide you with a sense of emotional security and well-being?

8. Do you feel your competence and skills are recognized by your partner?

9. Do you feel your partner does not share your interests and concerns? R

10. Do you feel your partner does not really rely on you for his or her well-being?

11. Could you turn to your partner for advice if you were having problems?

12. Do you feel you lack emotional closeness with your partner? 


\section{APPENDIX C \\ MOTIVATION TO CHANGE}

INSTRUCTIONS: Each statement describes how a person might feel when starting therapy or approaching problems in their lives. Please indicate the extent to which you tend to agree or disagree with each statement. In each case, make your choice in terms of how you feel right now, not what you have felt in the past or would like to feel. For all the statements, answer in terms of your offense and your ability to complete treatment. The words "here" and "this place" refer to treatment or the program at CCUSO. Please read the following statements carefully. For each statement, circle the number that best describes how much you agree or disagree with each statement.

Key: SD = Strongly Disagree, $\mathrm{D}=$ Disagree, $\mathrm{U}=$ Undecided or Unsure, $\mathrm{A}=$ Agree, $\mathbf{S A}=$ Strongly Agree

\begin{tabular}{lccccc} 
& SD & D & U & A & SA \\
\hline $\begin{array}{l}\text { 1. As far as I'm concerned, I don't have any problems that } \\
\text { need changing. }\end{array}$ & 1 & 2 & 3 & 4 & 5 \\
\hline $\begin{array}{l}\text { 2. I think I might be ready for some self-improvement. } \\
\text { 3. I am doing something about the problems that had been } \\
\text { bothering me. }\end{array}$ & 1 & 2 & 3 & 4 & 5 \\
\hline
\end{tabular}

\begin{tabular}{|c|c|c|c|c|c|}
\hline 4. It might be worthwhile to work on my problem. & 1 & 2 & 3 & $\overline{4}$ & 5 \\
\hline $\begin{array}{l}\text { 5. I'm not the problem one. It doesn't make much sense } \\
\text { for me to be here. }\end{array}$ & 1 & 2 & 3 & 4 & 5 \\
\hline
\end{tabular}
6. It worries me that I might slip back on a problem I have already changed, so I am here to seek help.

\begin{tabular}{lllllll}
\hline 7. I am finally doing some work on my problem. & 1 & 2 & 3 & 4 & 5
\end{tabular}
\begin{tabular}{lllllll}
\hline 8. I've been thinking that I might want to change something & 1 & 2 & 3 & 4 & 5
\end{tabular} about myself.

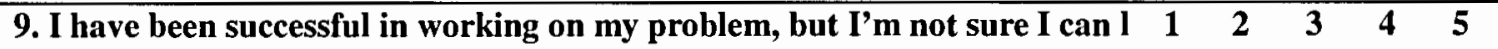 effort on my own.

\begin{tabular}{llllll}
\hline 10. At times my problem is difficult, but I'm working on it. & 1 & 2 & 3 & 4 & 5 \\
\hline $\begin{array}{l}\text { 11. Being here is pretty much a waste of time for me } \\
\text { because the problem doesn't have to do with me. }\end{array}$ & 1 & 2 & 3 & 4 & 5
\end{tabular}

12. I'm hoping this place will help me to better understand myself.

$\begin{array}{lllll}1 & 2 & 3 & 4 & 5\end{array}$


13. I guess I have faults, but there's nothing that I really

$\begin{array}{lllll}1 & 2 & 3 & 4 & 5\end{array}$

need to change.

\begin{tabular}{l|ccccc}
\hline 14. I am really working hard to change. & 1 & 2 & 3 & 4 & 5 \\
\hline 15. I have a problem and I really think I should work at it. & 1 & 2 & 3 & 4 & 5 \\
\hline $\begin{array}{l}\text { 16. I'm not following through with what I had already changed as well as I t } \\
\text { and I'm here to prevent a relapse of the problem. }\end{array}$ & 2 & 3 & 4 & 5
\end{tabular}

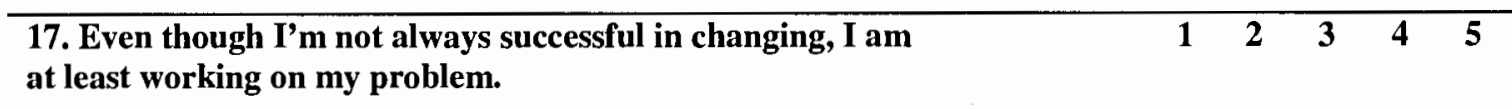

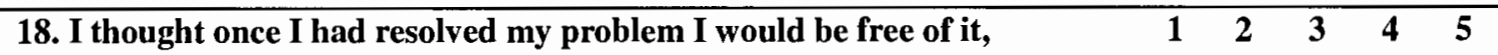
but sometimes I still find myself struggling with it.

19. I wish I had more ideas on how to solve the problem.

$\begin{array}{lllll}1 & 2 & 3 & 4 & 5\end{array}$

\begin{tabular}{|lllllll}
\hline 20. I have started working on my problems, but I would like help. & & 1 & 2 & 3 & 4 & 5
\end{tabular}

\begin{tabular}{lllllll}
\hline 21. Maybe this place will be able to help me. & 1 & 2 & 3 & 4 & 5
\end{tabular}

\begin{tabular}{lllllll}
\hline 22. I may need a boost right now to help me maintain the changes & 1 & 2 & 3 & 4 & 5
\end{tabular}

I've already made.

\begin{tabular}{|c|c|c|c|c|}
\hline 23. I may be part of the problem, but I don't really think I am. & 12 & 3 & 4 & 5 \\
\hline 24. I hope that someone here will have some good advice for me. & 1 & 3 & 4 & 5 \\
\hline $\begin{array}{l}\text { 25. Anyone can talk about changing; I'm actually doing something } \\
\text { about it. }\end{array}$ & 1 & 3 & 4 & 5 \\
\hline
\end{tabular}

\begin{tabular}{lllllll}
\hline 26. All this talk about psychology is boring. Why can't people just forget abr & 1 & 2 & 3 & 4 & 5
\end{tabular} problems?

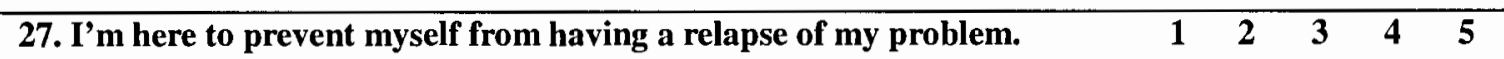

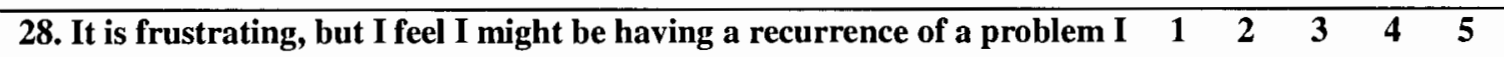
had resolved.

29. I have worries, but so does the next guy. Why spend time thinking about them?

\begin{tabular}{l|ccccc}
\hline 30. I am actively working on my problem. & 1 & 2 & 3 & 4 & 5 \\
\hline 31. I would rather cope with my faults than try to change them. & 1 & 2 & 3 & 4 & 5 \\
\hline $\begin{array}{l}\text { 32. After all I had done to try to change my problem, every now and again it } \\
\text { back to haunt me. }\end{array}$ & 2 & 3 & 4 & 5 \\
\hline
\end{tabular}




\section{APPENDIX D}

\section{MARLOWE-CROWNE SOCIAL DESIRABILITY SCALE}

Listed below are a number of statements concerning personal attitudes and traits. Read each item and decide whether the statement is true or false as it pertains to you personally.

1. Before voting, I thoroughly investigate the qualifications of all candidates.

True or False

2. I never hesitate to go out of my way to help someone in trouble.

True or False

3. It is sometimes hard for me to go on with my work if I am not encouraged.

True or False

4. I have never intensely disliked anyone.

True or False

5. On occasion, I have had doubts about my ability to succeed in life.

True or False

6. I sometimes feel resentful when I don't get my way.

True or False

7. I am always careful about my manner of dress.

True or False

8. My table manners at home are as good as when I eat out in a restaurant.

True or False

9. If I could get into a movie without paying and be sure I was not seen I would probably do it.

True or False

10. On a few occasions, I have given up doing something because I thought too little of my ability.

11. I like to gossip at times.

True or False

True or False

12. There have been times when I feel like rebelling against people in authority even though I knew they were right.

True or False 
13. No matter who I'm talking to, I'm always a good listener.

\section{True or False}

14. I can remember "playing sick" to get out of something.

True or False

15. There have been occasions when I took advantage of someone.

True or False

16. I'm always willing to admit it when I make a mistake.

17. I always try to practice what I preach.

True or False

True or False

18. I don't find it particularly difficult to get along with loud mouthed, obnoxious people.

True or False

19. I sometimes try to get even rather than forgive and forget.

True or False

20. When I don't know something, I don't at all mind admitting it.

True or False

21. I am always courteous, even to people who are disagreeable.

True or False

22. At times I have really insisted on having things my own way.

True or False

23. There have been occasions when I feel like smashing things.

True or False

24. I would never think of letting someone else be punished for my wrong doings.

True or False

25. I never resent being asked to return a favor.

True or False

26. I have never been irked when people expressed ideas very different from my own.

True or False 
27. I never make a long trip without checking the safety of my car.

$$
\text { True or False }
$$

28. There have been times when I was quite jealous of the good fortune of others.

True or False

29. I have almost never felt the urge to tell someone off.

True or False

30. I am sometimes irritated by people who ask favors of me.

$$
\text { True or False }
$$

31. I have never felt that I was punished without cause.

True or False

32. I sometimes think when people have misfortune they only got what they deserved.

True or False

33. I have never deliberately said something that hurt someone's feelings.

True or False 


\section{APPENDIX E}

\section{SELF-DEFEATING BEHAVIOR QUESTIONNAIRE}

Please circle the response that best answers the following questions in terms of how often you have experienced certain thoughts or behaviors in the last 90 days.

R-In the last 90 days, to what degree have you found it difficult to control or stop your inappropriate sexual thoughts?

Not at all difficult

12

23

Extremely difficult

4

5

R-In the last 90 days, to what degree have you found it difficult to get along well with others?

Not at all difficult

12

3

Extremely difficult

$4 \quad 5$

R-In the last 90 days, to what degree have you been distracted by sexual thoughts and fantasies?

Not at all distracted

12

3

Extremely distracted

$4 \quad 5$

R-In the last 90 days, to what degree have you found it difficult to cooperate in treatment?

Not at all difficult

1

Extremely difficult

4 


\section{For the next set of questions, please answer in terms of how you feel currently.}

What do you think the probability is that you will be released?

Definitely won't

12

3

4

Definitely will 5

How motivated are you to successfully complete treatment and be released?

Not at all motivated

12
Extremely motivated

4

R-What level of anxiety, if any, do you have about being released into the community?

Not at all anxious

12

3

Extremely anxious

4 5

To what degree are you aware that your behaviors here at CCUSO help or hurt your treatment progress?

Not at all aware

2 


\section{APPENDIX F}

\section{RECORD REVIEW FORM}

Record Review Form

Participant \#

\begin{tabular}{|c|c|c|c|c|c|c|c|}
\hline & & & 2 & 3 & 4 & 5 & 6 \\
\hline ge Range & $18-25$ & $26-32$ & $33-4$ & & -50 & $51-65$ & 5 \\
\hline
\end{tabular}

Length of Commitment (months)

Treatment Phase (in order from most recent to oldest)

Current phase___ Length in Current Phase

Phase Length in Phase

Phase Length in Phase

Phase Length in Phase

Phase Length in Phase

Phase Length in Phase

Phase Length in Phase

Phase Length in Phase 


\section{0-Day Treatment Evaluations}

1. Disclosure

2. Insight

3. Personal Victimization

4. Empathy

5. Health, Hygiene, \& Leisure

6. Cognitive Coping Skills

7. Sexual Behaviors

8. Relapse Prevention

9. Intimacy Skills

10. Problem Solving Skills

Total Average

Dynamic/Stable Risk Factors

A. Significant Social Influences

(Positive/Negative)

B. Intimacy Deficits: $(0=$ No, $1=$ Yes $)$

a. Emotional Identification with Children

b. Hostility Toward Women

c. General Social Rejection/Loneliness

d. Lack of Concern for Others

C. Sexual Self-Regulation Problems: $(0=$ No, $1=$ Yes $)$

a. Sex Drive/Preoccupation

b. Sex as Coping

c. Deviant Sexual Interests

D. Cooperation with Supervision

E. General Self-Regulation: $(0=$ No, $1=$ Yes $)$

a. Impulsive Acts

b. Poor Cognitive Problem Solving Skills

c. Negative Emotional/Hostility

Dynamic/Acute Risk Factors (No Problem $=0$, Some Problem =1, Definite Problem = 2)

1. Victim Access

2. Emotional Collapse

3. Collapse of Social Support 
4. Hostility

5. Substance Abuse

6. Sexual Preoccupations

7. Rejection of Supervision

8. Unique factor 
APPENDIX G

10 TREATMENT AREAS

Description of the Ten Treatment Area Requirements for obtaining each "point" (1 through 8).

\section{Disclosure:}

The degree to which he has thoroughly DISCLOSED his sexual behavior and offense history:

\begin{tabular}{|c|c|}
\hline Skills & $\begin{array}{l}1=\text { Patient can define purpose of disclosure, verbally or writing. } \\
2=\text { Patient participates in disclosure group, more often than not, and } \\
\text { maintains a disclosure log. } \\
3=\text { Patient has passed the } 4 \text { basic polygraphs. }\end{array}$ \\
\hline Demonstration & $\begin{array}{l}\text { 4= Patient has demonstrated an understanding of the disclosure format and } \\
\text { process ( } 75 \% \text { of groups). } \\
5=\text { Patient has disclosed his offenses in group and passed specific-offense } \\
\text { polygraphs as required. } \\
6=\text { Patient has consistently disclosed offenses in group ( } 75 \% \text { of groups) } \\
7=\text { Patient has consistently given constructive feedback to others in } \\
\text { disclosure groups. }\end{array}$ \\
\hline egration & $\begin{array}{l}8=\text { Patient has passed polygraphs on use of violent and masturbatory } \\
\text { fantasies, and maintenance polygraphs, and has disclosed these during } \\
\text { group sessions. }\end{array}$ \\
\hline
\end{tabular}

\section{Insight:}

The degree to which he has shown INSIGHT into the various social, behavioral, emotional, and cognitive factors that contributed to his offending behavior, and recognizes his vulnerabilities and his cycle of abuse:

Skills $\quad 2=$ Patient can report several factors that can lead to sex offending.

$1=$ Patient can report verbally or in writing what a factor list is. $3=$ Patient recognizes and has created a preliminary list of the various factors that contributed to his sexual offending. $4=$ Patient has consistently demonstrated in group the use of factors when describing his offending behavior, including his family and relationship history.

Demonstration 5= Patient can explain how these factors affect his behavior on the unit, verbally or in writing and have it approved by therapist.

$6=$ Patient consistently demonstrates knowledge of these factors by demonstrating appropriate behavior on the unit and in groups (no behavior reports). 
$7=$ Patient can identify contributing cognitive and emotional factors that impact other patient's behaviors.

Integration $\quad 8=$ Patient has a thorough understanding of the cognitive and emotional factors behind his sexual offending and others by consistently demonstrating this in groups (75\% of groups) and by submitting an approved complete factors list to his therapist. This information should be integrated in relapse prevention plan.

\section{Personal Victimization}

The degree to which he appears to have resolved past traumas, resentments, and other forms of PERSONAL VICTIMIZATION:

Skills $\quad 2=$ Patient has shared in group, at least twice, some resentments and

$1=$ Patient can report verbally or in writing what a resentment and personal victimization list is. personal victimization.

$3=$ Patient has created a resentment list and personal victimization list and has shared them in group. This should be submitted to a therapist for approval.

$4=$ Patient has consistently identified when discussing his behavior on the unit and in describing his offenses, how his resentments and personal victimization impact his behavior (75\% of groups).

Demonstration 5= Patient has worked to reduce anger, hostility, and resentment toward victimizers by demonstrating in group verbally or in writing alternative understandings of his victimizers actions toward him, which has been approved by his therapist.

$6=$ Patient demonstrates through behavior on the unit a reduction in anger, hostility, and resentment toward victimizers by not displaying inappropriate anger and hostility.

$7=$ Patient can, in group and on the unit, identify in others how their personal victimization and resentments have impacted their behavior.

Integration $\quad 8=$ Patient has shown significant healing and resolution of resentments toward identified victimizers by consistently demonstrating it in groups (75\% of groups) and on the units (no behavior reports) and has included aspects of this in his relapse prevention plan.

\section{Empathy:}

The degree to which he has shown EMPATHY, remorse, and an understanding of the impact of his sexual offending and accepts full responsibility for his behavior: 
$4=$ Patient consistently takes responsibility for all his past offense/offenses in group (75\% of all groups).

Demonstration $5=$ Patient has a good understanding of the ways in which victims suffer from sexual abuse and expresses some feelings of remorse verbally or in writing.

$6=$ Patient consistently demonstrates in groups (75\% of all groups) the ability to state another persons' perspective and take responsibility for his actions.

$7=$ Patient demonstrates on the units, through his behavior towards others, an understanding of their perspectives, as well as taking responsibility for his actions. Demonstrated by no behavior reports.

Integration $\quad 8=$ Patient takes full responsibility for his past behavior and demonstrates in writing the impact that his sexually violent crimes have upon his victims.

\section{Health, Hygiene, and Leisure Skills}

The degree to which he has demonstrated acceptable HEALTH AND HYGEINE practices and developed meaningful personal goals, LESIURE SKILLS, and activities that will meet his existential needs:

$1=$ Patient can identify verbally or writing good health, hygiene and leisure skills plan.

Skills $\quad 2=$ Patient successfully develops a good health, hygiene, and leisure skills plan.

$3=$ Patient implements good health, hygiene and leisure skills plan at least once a week.

4= Patient consistently implements good health, hygiene and leisure skills plan (75\% of all days).

Demonstration 5= Patient identifies in writing a list of leisure skills to be used currently or upon release and submits it to his therapist for approval.

$6=$ Patient can identify all health concerns and the ongoing treatment requirements.

$7=$ Patient can identify and state the reason why he takes all of his medications (scores adjusted for those who do not take medications)

Integration $\quad 8=$ Patient has additional leisure interests planned for release. Relapse prevention plan includes a section on how patient will maintain wellness or a healthy balance of body, mind, and spirit (e.g. attention to improving/maintaining physical health in form of an exercise plan or healthy nutrition, ideas for healthy social interaction, support groups, etc.).

\section{Cognitive Coping Skills}

The degree to which he demonstrates good internal COGNITIVE COPING SKILLS and anger management, and had reduced cognitive distortions: 
1= Patient can define cognitive coping skills and cognitive distortions, verbally or in writing.

Skills $\quad 2=$ Patient can state verbally or writing why cognitive coping skills are important in understanding sex offending and devleop0s a list of cognitive distortions that can lead to sex offending.

$3=$ Patient accepts the principle that others are not responsible for his feelings and behaviors by not receiving any behavior reports and by demonstrating this in groups at least 3 times and submits a list to his therapist for approval.

$4=$ Patient displays good cognitive coping skills, more often than not, in groups.

Demonstration 5= Patient displays good cognitive coping skills, more often than not, on the units.

$6=$ Patient is able to consistently identify other patients' cognitive distortions (75\% of all groups).

$7=$ Patient consistently ( $75 \%$ of all groups) provides constructive feedback on how other patients can use cognitive coping skills.

Integration $\quad 8=$ Patient is able to de-escalate himself using internal cognitive coping skills to re-interpret events and is able to identify the internal cognitive coping strategies he uses while not suppressing his feelings. This is demonstrated by no behavior reports and consistent demonstration in groups (75\% of all groups). Good cognitive coping skills should be included in relapse prevention plan, as well the cognitive distortions.

\section{Sexual Behaviors:}

The degree to which he has recognized and altered his dysfunctional SEXUAL BEHAVIORS and beliefs:

Skills $\quad 2=$ Patient has successfully completed Arousal Management curriculum.

$3=$ Patient has abstained from problematic sexual behavior and inappropriate sexual talk from one year.

$4=$ Patient uses a variety arousal management techniques.

Demonstration 5= Patient has valid PPGs and/or ABELs and has used behavior techniques to reduce deviant arousal.

$6=$ Patient consistently demonstrates in groups ( $75 \%$ of all groups) an understanding and use of arousal management techniques.

$7=$ Patient has demonstrated through PPG and/or ABEL a positive change in arousal patterns.

Integration $\quad 8=$ Patient has stated no deviant sexual beliefs for six months and has significantly reduced deviant arousal as measured by the PPG and/or ABEL. 


\section{Relapse Prevention:}

The degree to which he has developed a comprehensive RELAPSE PREVENTION PLAN:

Skills

$1=$ Patient can define either verbally or in writing relapse prevention.

$2=$ Patient can define in writing the basic components of relapse prevention.

$3=$ Patient has completed a thorough autobiography and shared it with the group

$4=$ Patient has consistently participated ( $75 \%$ of all groups) by giving and receiving feedback in his assigned relapse prevention group, completed assigned homework and demonstrated a basic understanding how problems are related to one another through a cycle of behaviors.

Demonstration $5=$ Patient demonstrates a thorough understanding into his dysfunctional and sexual assault cycle by being able to share thoughts/feelings/behaviors as they relate to each of the steps within his cycle. This should be submitted to the therapist for approval.

$6=$ Patient is able to identify and display some basic interventions to interrupt the cycle as evidence by his interactions with peers and staff. $7=$ Patient submits a first draft of a comprehensive relapse plan to his therapist for approval. This relapse plan is based on the information learned and experiences in treatment.

Integration $\quad 8=$ Patient has participated consistently in groups (75\% of groups) and completed assigned homework in an atmosphere of cooperation with peers and therapist. In anticipation of transitional release planning patient has developed a comprehensive relapse prevention plan that include a support systems and contingency plans that specifically identify potential internal and external high risk factors along with solid intervention strategies to avoid relapse. This plan has been submitted to and approved by his therapist.

\section{Intimacy Skills:}

The degree to which he has demonstrated good relationship and INTIMACY SKILLS:

$1=$ Patient can define verbally or in writing basic components of good relationships with intimacy skills.

Skills $\quad 2=$ Patient can identify at least here things that have impacted his ability to establish good relationship and intimacy skills.

$3=$ Patient demonstrates ability to get along with other patients and staff more often than not and has three or less behavior or incident reports in the past year. 
$4=$ Patient is able to identify several barriers verbally or in writing that have stopped him from expressing emotions to others.

Demonstration $5=$ Patient demonstrates ability, more often than not, to appropriately disclose feelings with others and gives, receives, and solicits appropriate feedback from his peers and can express the relationship between intimacy and sexual satisfaction.

$6=$ Patient demonstrates consistently in groups ( $75 \%$ of all groups) and on the units the ability to "actively listen" and give constructive feedback. $7=$ Patient consistently demonstrates ( $75 \%$ of the time) the ability to listen to others and have a mutually satisfying, empathetic relationships.

Integration $\quad 8=$ Patient has integrated his knowledge of relatedness, sexual satisfaction, control issues and self-esteem into his relapse prevention plan.

\section{Problem Solving Skills:}

The degree to which he has demonstrated good communication and PROBLEM SOLVING skills:

Skills

$1=$ Patient can define, verbally or in writing, the basic components of problems solving.

$2=$ Patient can express the importance of effective problem solving by identifying at least three situations where effective problems solving has been used on the units.

$3=$ Patient demonstrates, more often than not, ability to communicate fairly with other to solve problems in groups.

$4=$ Patient has, more often than not, demonstrated good problem solving skills on the units.

Demonstration $5=$ Patient consistently demonstrates ( $75 \%$ of all groups) the ability to be assertive, without being aggressive or passive toward others and avoids manipulation and rule violation to get what he wants.

$6=$ Patient is able to identify good problem solving skills of others in group and can give constructive feedback to others.

$7=$ Patient consistently demonstrated the ability to identify and give constructive feedback to others on problem solving. This will be demonstrated displaying this skill in $75 \%$ of all groups and by not having any behavior reports or incident reports for one year.

Integration $\quad 8=$ Patient demonstrates the ability to develop creative solutions and to solve problems and has included the relationship problem solving has to cognitive distortions and has integrated this information into his relapse prevention plan. 
APPENDIX H

FLIER

\section{Request for Participation in Research Study}

- What: Characteristics of Sex Offenders in Treatment

- When: DATE AND TIME

- Where: Bay Area

Researchers from the University of Northern Iowa will be here on DATE AND TIME to conduct a study on sex offenders in treatment. The study will be conducted in the Bay Area and all interested in participating will be given an overview of the study by the researchers. Participation is completely voluntary and all individuals who choose to participate in the study will be compensated for their time with a $\$ 5$ activity punch ticket. This study is separate from CCUSO and all information collected will be confidential; therefore, staff will not have access to any of the information. 


\begin{abstract}
APPENDIX I
STAFF MEMBER STATEMENT

CCUSO Staff Member,

Please recite this statement verbatim to individuals on DATE @ TIME:

"Researchers from the University of Northern Iowa request your participation in a study on characteristics of sex offenders in treatment. The study will be conducted during your formal study hour and will be considered part of your formal study hour if you choose to participate. The study will occur in the Bay Area and all who choose to participate will be compensated for their time with a $\$ 5$ activities punch ticket. This study is separate from CCUSO and your participation is completely voluntary. All information collected will be confidential and staff from CCUSO will not have any access to the information. If you are interested in participating, the study will be conducted in the Bay Area at DATE @ time where the researchers will give an overview of the study.
\end{abstract}

We appreciate your cooperation with this study. This research will be useful in determining factors related to treatment outcome of sex offenders and a presentation of the findings will be presented in the fall to all staff and participants who wish to attend.

Best,

Cassie Nieman and Ashley Helle 


\section{APPENDIX J}

\section{STATEMENT OF PURPOSE}

Hi. We are conducting some research today on characteristics of people who have been civilly committed. We have surveys to be filled out which take about 45 minutes to an hour. If you choose to participate, we will give you a $\$ 5$ activity punch ticket as compensation for your time. This study does not have any impact on your treatment here at CCUSO and none of the staff or administrators will have access to your responses. This study will count as part of your formal study hour. 


\title{
APPENDIX K
}

\section{INFORMED CONSENT}

\section{UNIVERSITY OF NORTHERN IOWA INFORMED CONSENT}

\author{
Project Title: Treatment Outcomes for Sexual Offenders who are Civilly Committed \\ Name of Investigator(s): Ashley Helle \& Cassie Nieman
}

Invitation to Participate: You are invited to participate in a research project conducted through the University of Northern Iowa. The University requires that you give your signed agreement to participate in this project. The following information is provided to help you make an informed decision about whether or not to participate.

Nature and Purpose: The purpose of this study is to examine factors that may influence treatment in a rehabilitation center.

Explanation of Procedures: If you choose to participate you will be asked to fill out a packet of assessments. This will take approximately one hour to an hour and a half to complete. If you decide to participate, researchers will also be collecting select information from your treatment files which will include previously completed assessments already in your file (MMPI-2, RRASOR, ACUTE, STABLE, MnSTOT-R, STATIC-99, MSI-I), treatment phases, length of time in current phase, offense history, behavioral reports, and diagnoses.

Discomfort and Risks: There are some risks for participation in this study including possible psychological distress from reporting information about you. These risks are not expected to be more than those associated with daily living and may not be present for some participants. If you include any incriminating information other than what is directly asked of you (example: details of a previous crime that has not been disclosed previously) on the assessments, this information may be reported to appropriate staff. If at any time you appear distressed or report either verbally or in written form the intent to harm yourself or another individual, staff will be notified. If at any time you find the study stressful, let us know.

Benefits and Compensation: There are no direct benefits to you as a result of this study. There will be a $\$ 10$ activity punch ticket provided as compensation for your time for those who participate.

Confidentiality: Information obtained during this study which could identify you will be kept strictly confidential. The overall findings with no identifying information may be published in an academic journal or presented at a scholarly conference. This study is separate from CCUSO and the data will not be seen or collected by facility personnel. If at any time you appear distressed or report either verbally or in written form the intent to harm yourself or another individual, staff will be notified.

Right to Refuse or Withdraw: Your participation is completely voluntary. You are free to withdraw from participation at any time or to choose not to participate at all, and by doing so, you will not be penalized or lose benefits to which you are otherwise entitled.

Future Use of Data: It is possible that these data may be used as a comparison group for future studies examining sexual offenders. All identifying information will be removed and all data will be confidential. As with the current study, future publications or presentations will not include any identifying information. 
Questions: Any questions about the study can be directed to the primary investigators, Ashley Helle and Cassie Nieman at 319-273-2303 or the project investigator's faculty advisors, Dr. John Williams and Dr. Kim MacLin at the Department of Psychology, University of Northern Iowa 319-273-2303. You can also contact the office of the IRB Administrator, University of Northern Iowa, at 319-273. 6148, for answers to questions about rights of research participants and the participant review process. If you feel discomfort at any time during the study, please report to staff members or call any of the numbers listed above after the study.

Please read the following carefully. The first signature is agreement to participate in this current study:

I am fully aware of the nature and extent of my participation in this project as stated above and the possible risks arising from it. I agree to participate in this project. I acknowledge that I have received a copy of this consent statement. I am 18 years of age or older.

Would you like to participate in this research study? (Please circle one) YES NO $\mathrm{X}$

(Signature of Participant)

(Date) (Printed Name of Participant)

(Date)

(Signature of Researcher)

(Date)

(Printed Name of Faculty Advisor)

(Date)

The second signature is your consent for the researchers to access the following records:

MMPI-2 (personality test), RRASOR, ACUTE, STABLE, MnSTOT,-R, STATIC-99, MSI-I, behavioral reports, treatment phases, time in current treatment phase, and offense history.

Do you consent to have your records accessed? (Please circle one) YES NO

$\mathrm{X}$

(Signature of Participant)

(Date) (Printed Name of Participant)

(Date)

$\mathrm{X}$

(Signature of Researcher)

(Date) (Printed Name of Faculty Advisor)

(Date) 
APPENDIX L

NAME SHEET

Name:

(This paper will be shredded and thrown away after collected data has been matched with the data on file; therefore, no identifying information will be kept). 